\title{
THE FIRST INTERNATIONAL TREATY OF THE DEMOCRATIC REPUBLIC OF GEORGIA AND ITS ECONOMIC ASPECTS
}

\section{SIMON TAVARTKILADZE}

\section{Doctor of Economics}

European University's Institute for Research of Economic and Social Problems of Globalization, Georgia amiran_reg@hotmail.com

Abstract. The first international treaty of the Democratic Republic of Georgia was concluded two days after Georgiass declaration of independence on May 28, 1918.

Under this agreement, Georgia received a kind of «guarantee of favor» from the German Empire that it would protect the international recognition of the newly established Democratic Republic of Georgia.

Declaring independence for the country is an important but still not sufficient event. Given the difficult economic and social background, the government of the Democratic Republic of Georgia had to prove that the country could maintain and strengthen its independence.

The "Poti agreement" was not the only first international treaty of the Democratic Republic of Georgia, but also the determination of the content of all further international actions. As far as Germany was presented as a party, it was significant for other countries as well, thus practically obligatory for the allied countries of Germany.

The existence of the treaty of Georgia was crucial and the establishment of independence, de facto and de jure recognition of the country was considerable for other countries.

It is also quite clear that Germany was driven not only by political but also by economic interests in Georgia. But according to overall perception, these interests did not infringe Georgiass sovereignty and were not inconsistent with its national aspirations; Germany considered Georgia not as a satellite but as a partner with whom the cooperation was based on principles acceptable for both countries.

However, given the substance of the treaty, German stated obvious attraction and strong support towards small and weak country Georgia. Especially in problem solving and overcoming crisis in economic, industrial, trade, transport, mining, budget-finance, food provision, etc.

Thus, supported definition and establishment of geo-political and geo-economic space of the country.

KEYWORDS: INTERNATIONAL TREATY, DEMOCRATIC REPUBLIC OF GEORGIA, GEO-ECONOMIC SPACE.

For citation: Tavartkiladze, S. (2020). The First International Treaty of the Democratic Republic of Georgia and its Economic Aspects. Globalization and Business, №9, pp. 207-217 (In Georgian). https://doi.org/10.35945/gb.2020.09.026 


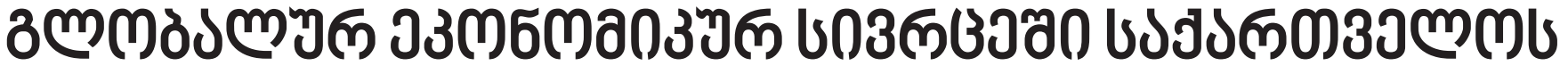

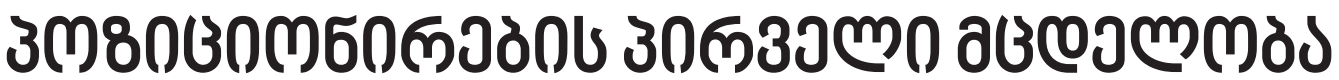

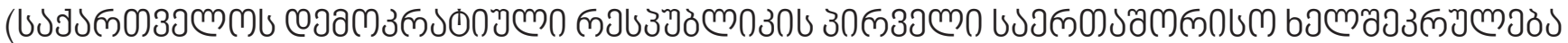

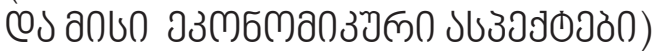

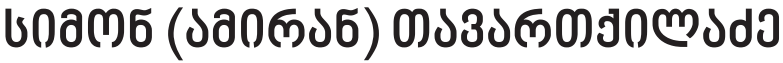

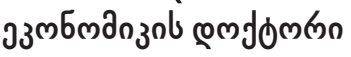

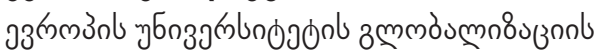

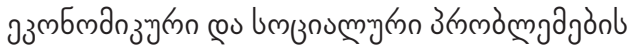

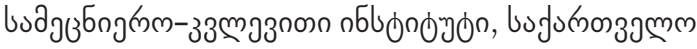

amiran_reg@hotmail.com

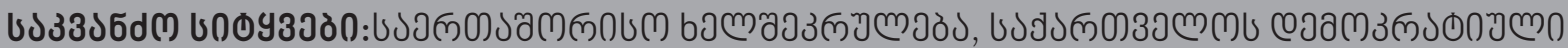

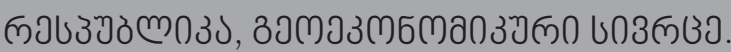

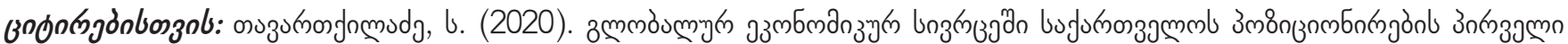

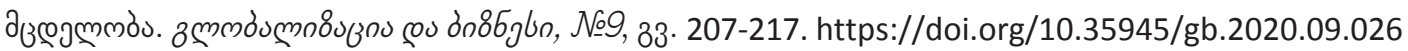

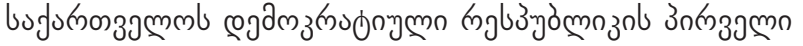

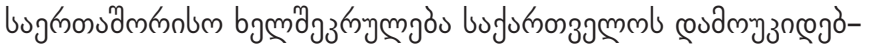

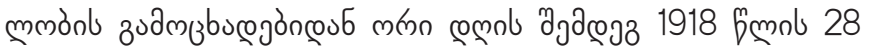
aunblesngem.

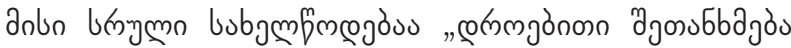

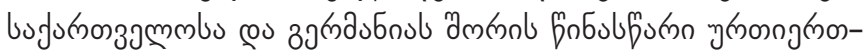

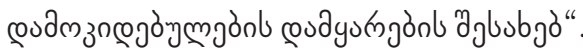

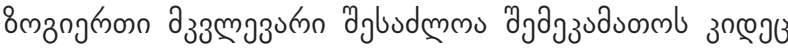

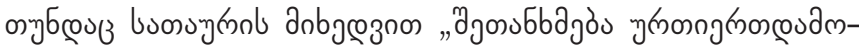

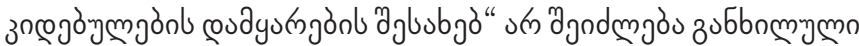

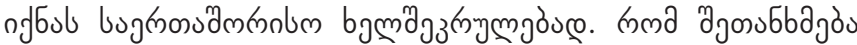

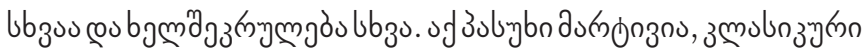

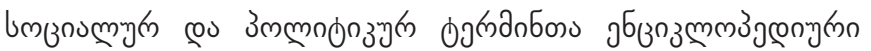

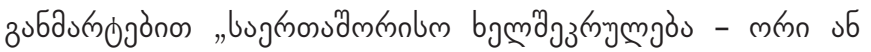

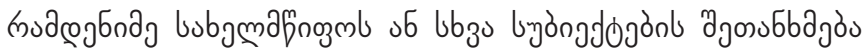

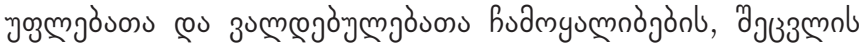

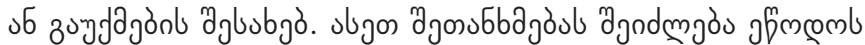

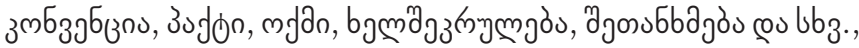

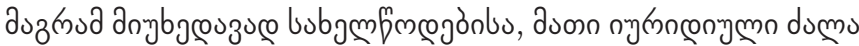
msbudsmos." (Social ...2004).

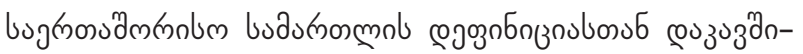

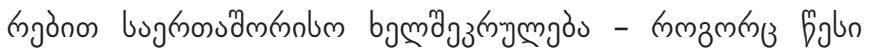

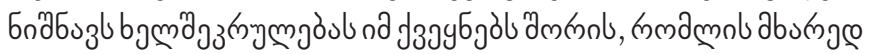

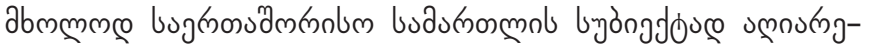

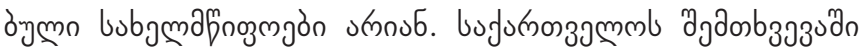

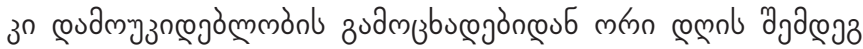

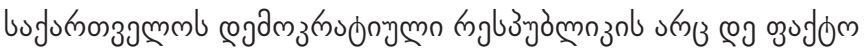

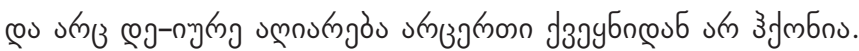

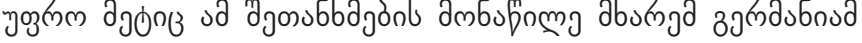

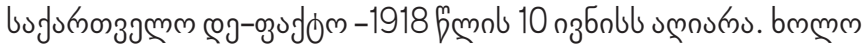

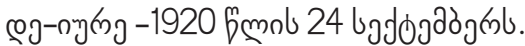

s з змб

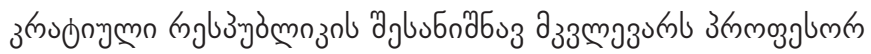

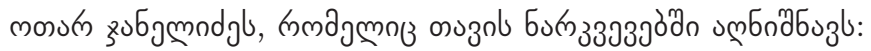

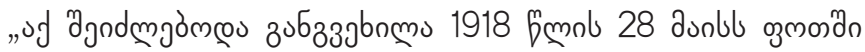

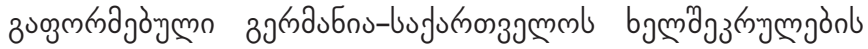

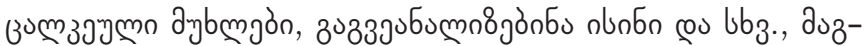

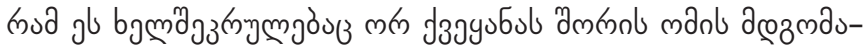

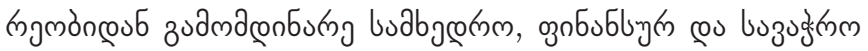

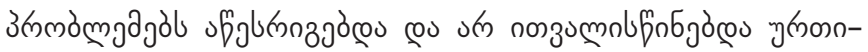

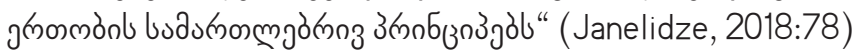

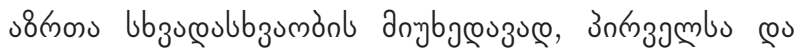

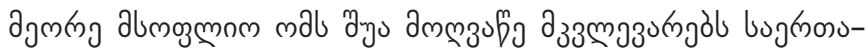

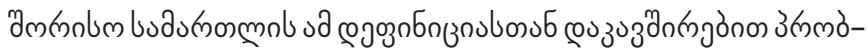

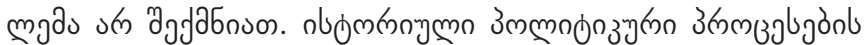

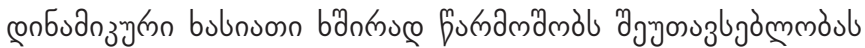

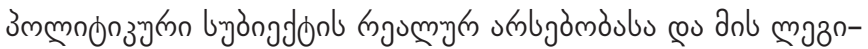

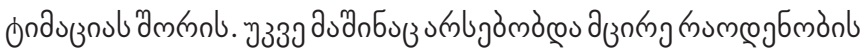

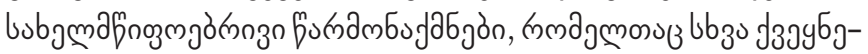

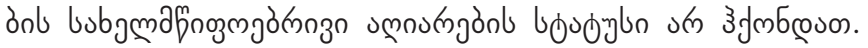

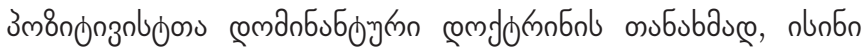

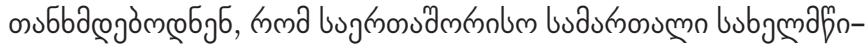

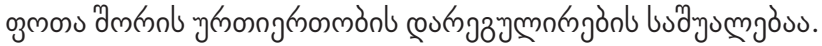

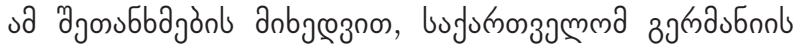

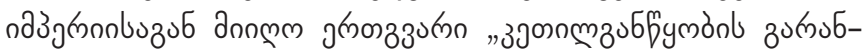

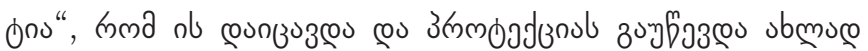




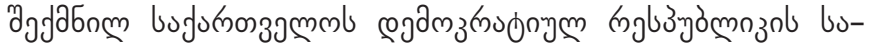

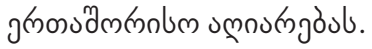

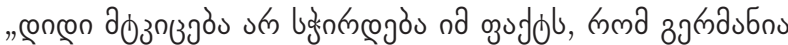

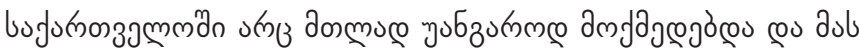

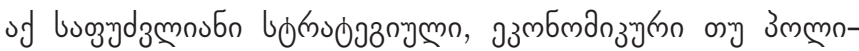

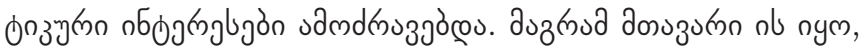

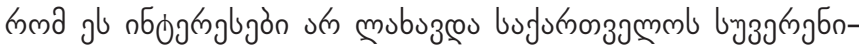

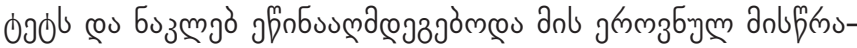

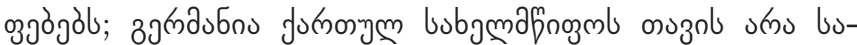

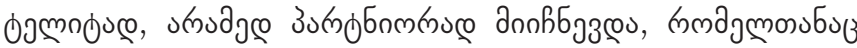

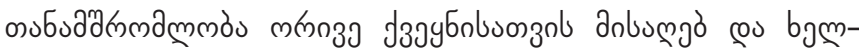

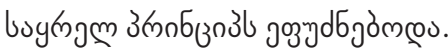

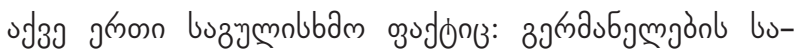

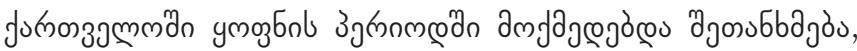

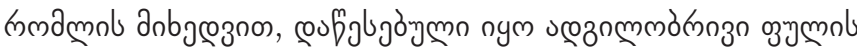

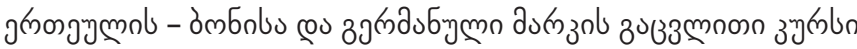

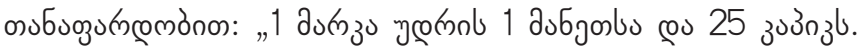

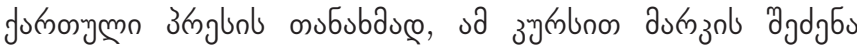

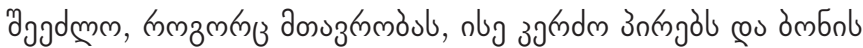

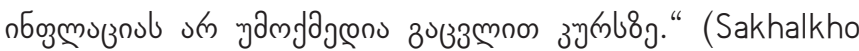
Sakme, 1919).

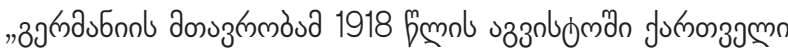

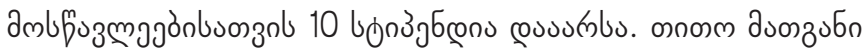

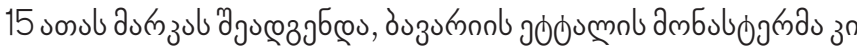

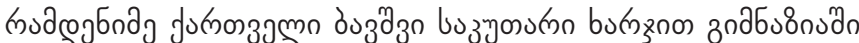

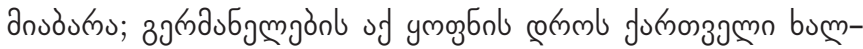

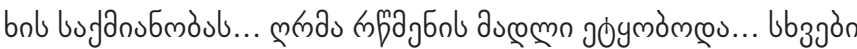

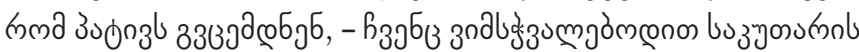

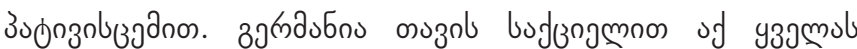

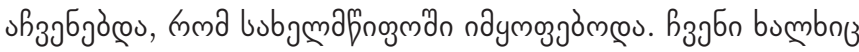

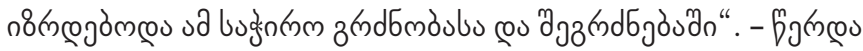

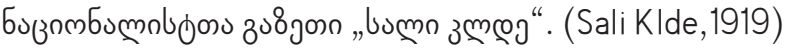

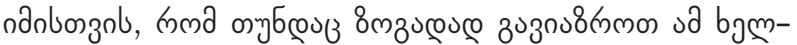

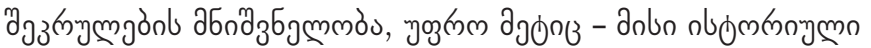

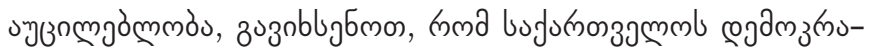

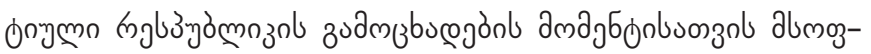

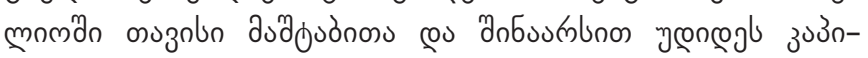

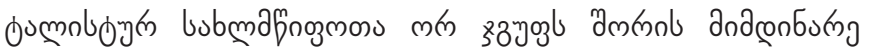

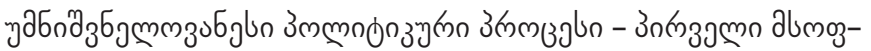
мпм мдे.

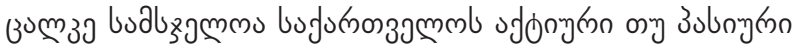

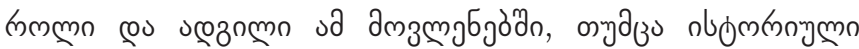

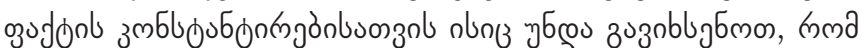

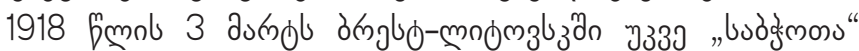

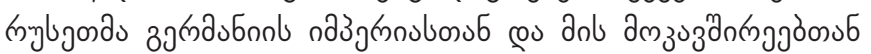

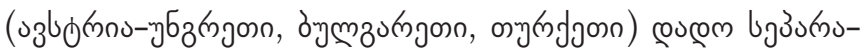

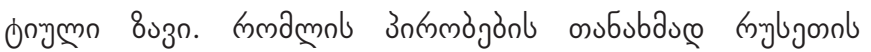

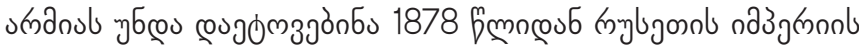

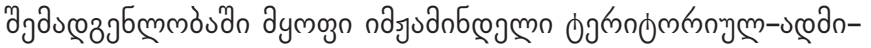

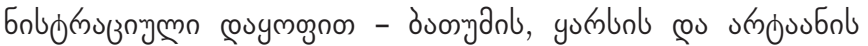

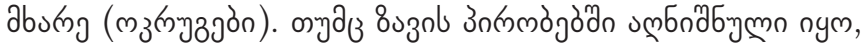

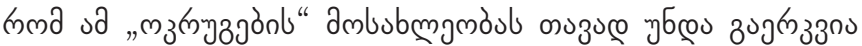

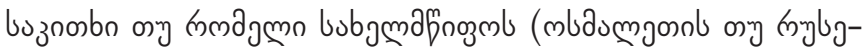

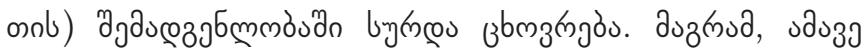

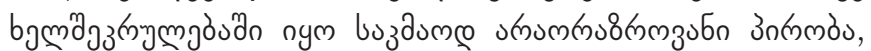

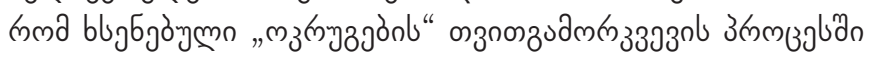

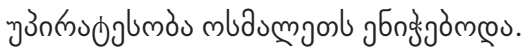

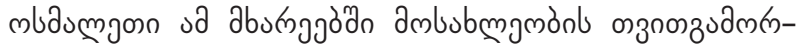

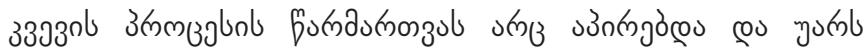

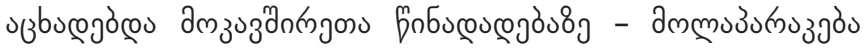

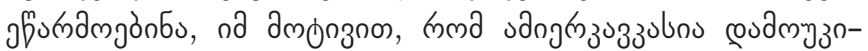

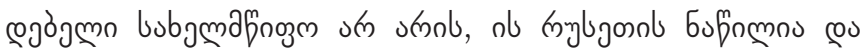

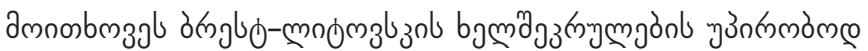
उदmòs.

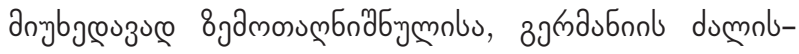

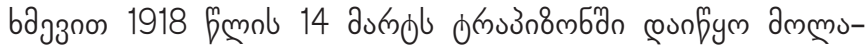

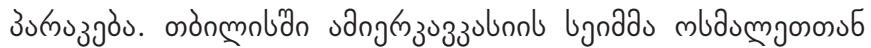

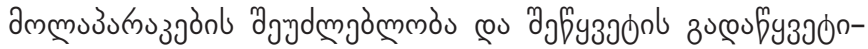

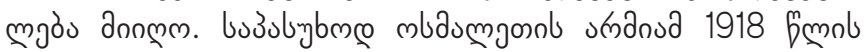

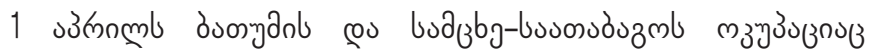

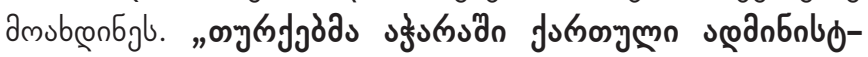

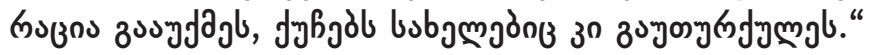
(Chumburidze, 2003:115)

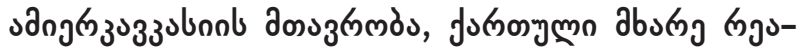

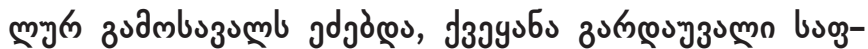

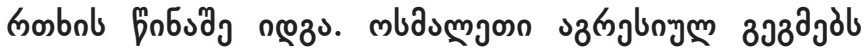

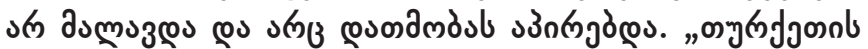

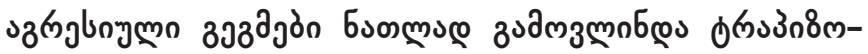

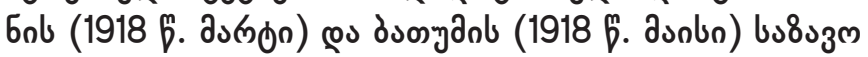

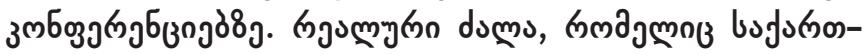

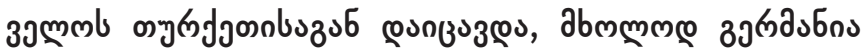

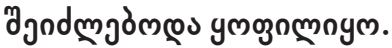

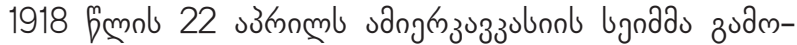

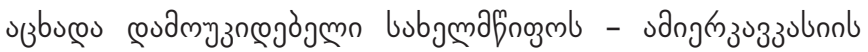

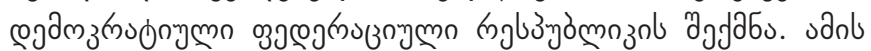

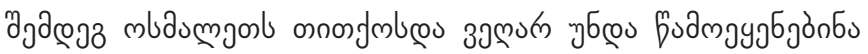

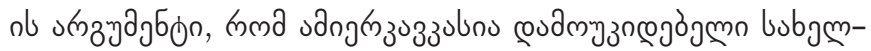

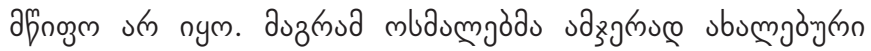

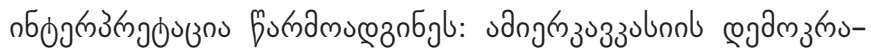

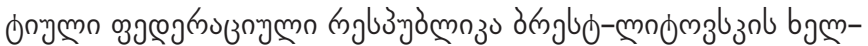

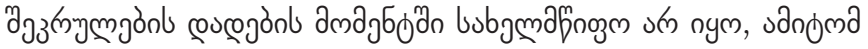

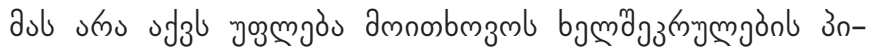

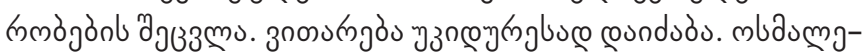

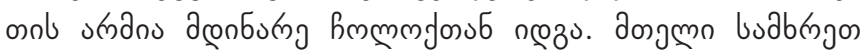

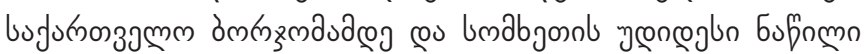

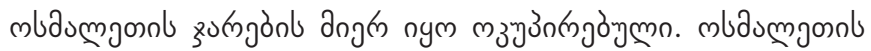

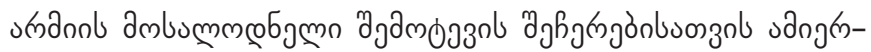

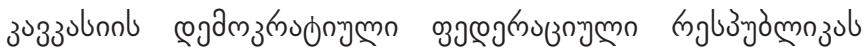

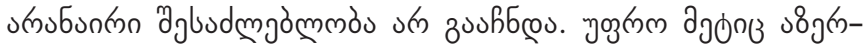

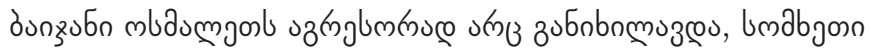




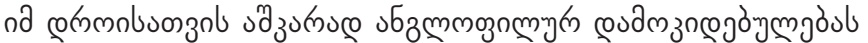

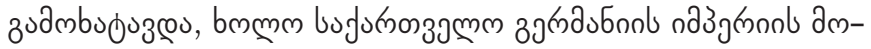
пудеg пум.

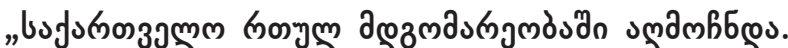

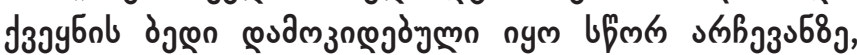

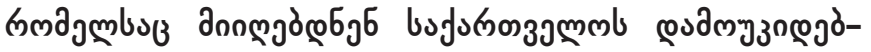
mmón a चб

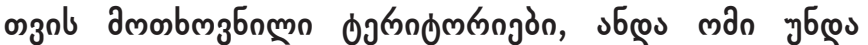

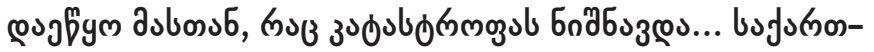

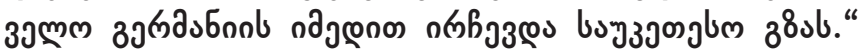
(History...2003:116).

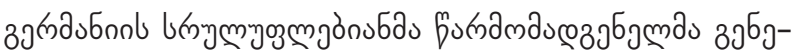

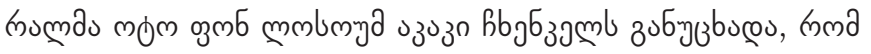

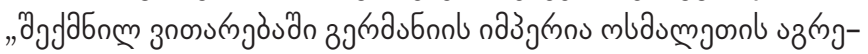

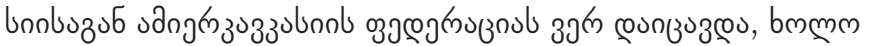

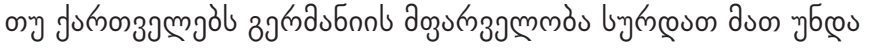

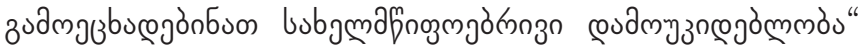

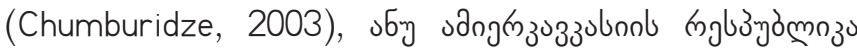

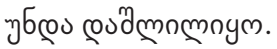

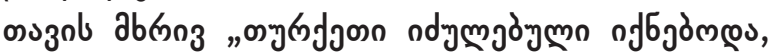

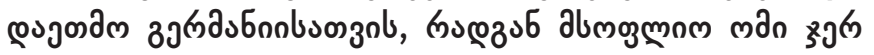

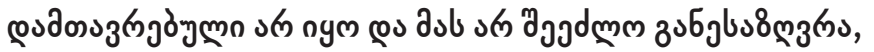

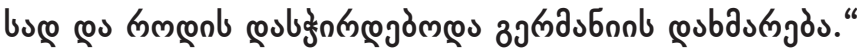
(History ...2003:576).

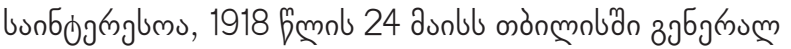

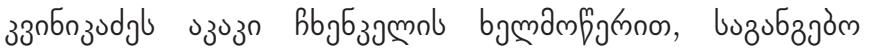

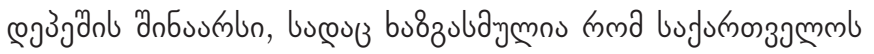

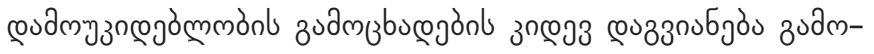
च

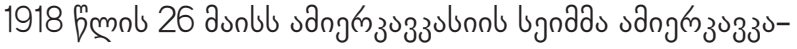

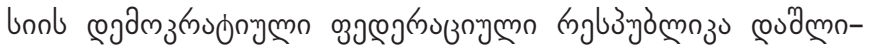

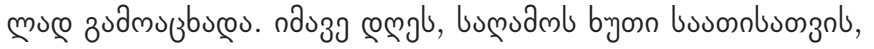

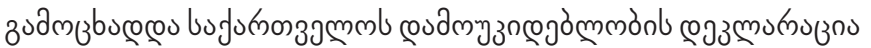

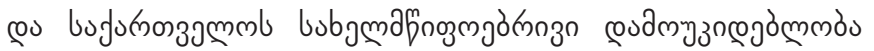

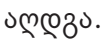

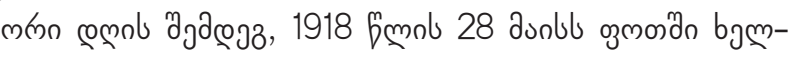

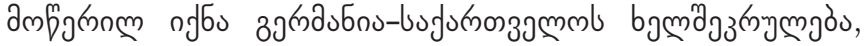

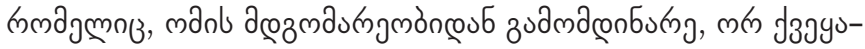

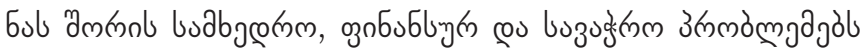
spjum

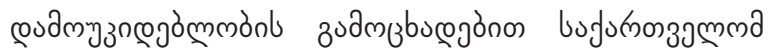
3j

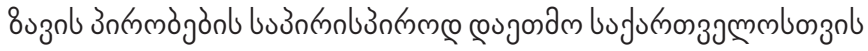

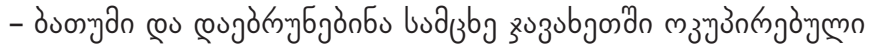

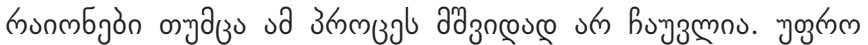

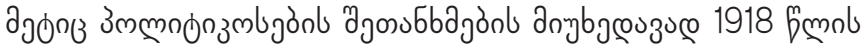

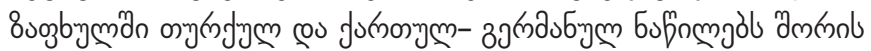

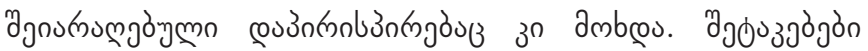

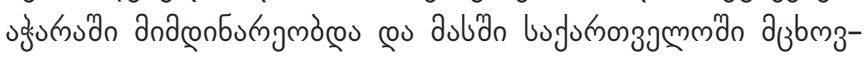

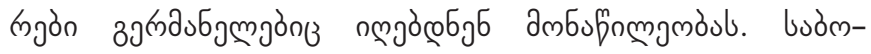

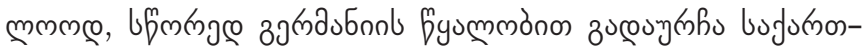

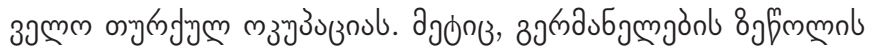

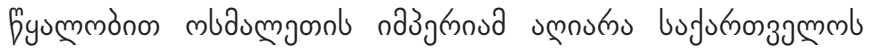

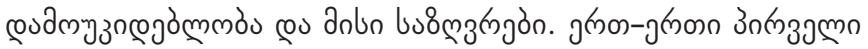

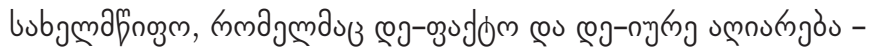

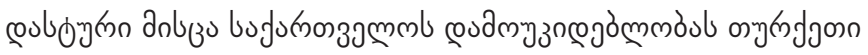
nym - 1918 pmonl 3 nzbolo.

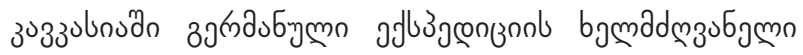

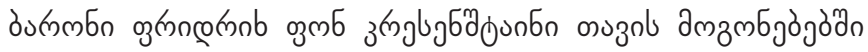

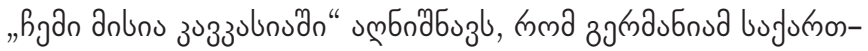

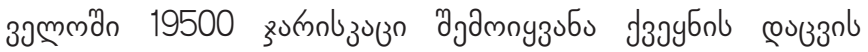

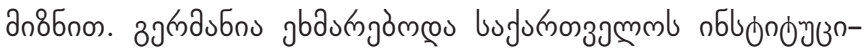

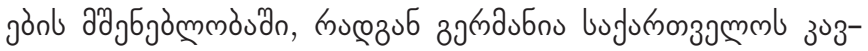

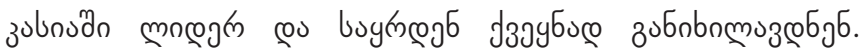

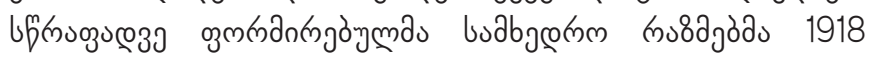

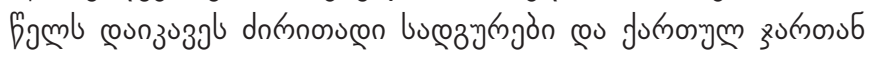

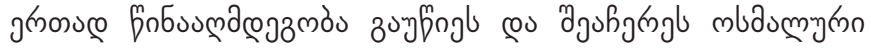

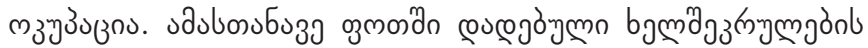

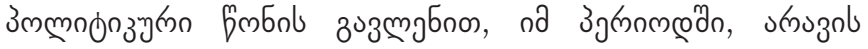

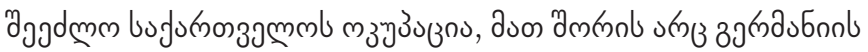

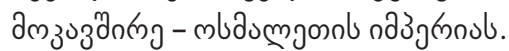

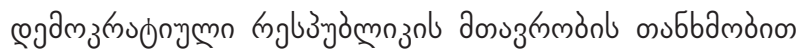

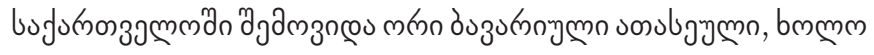

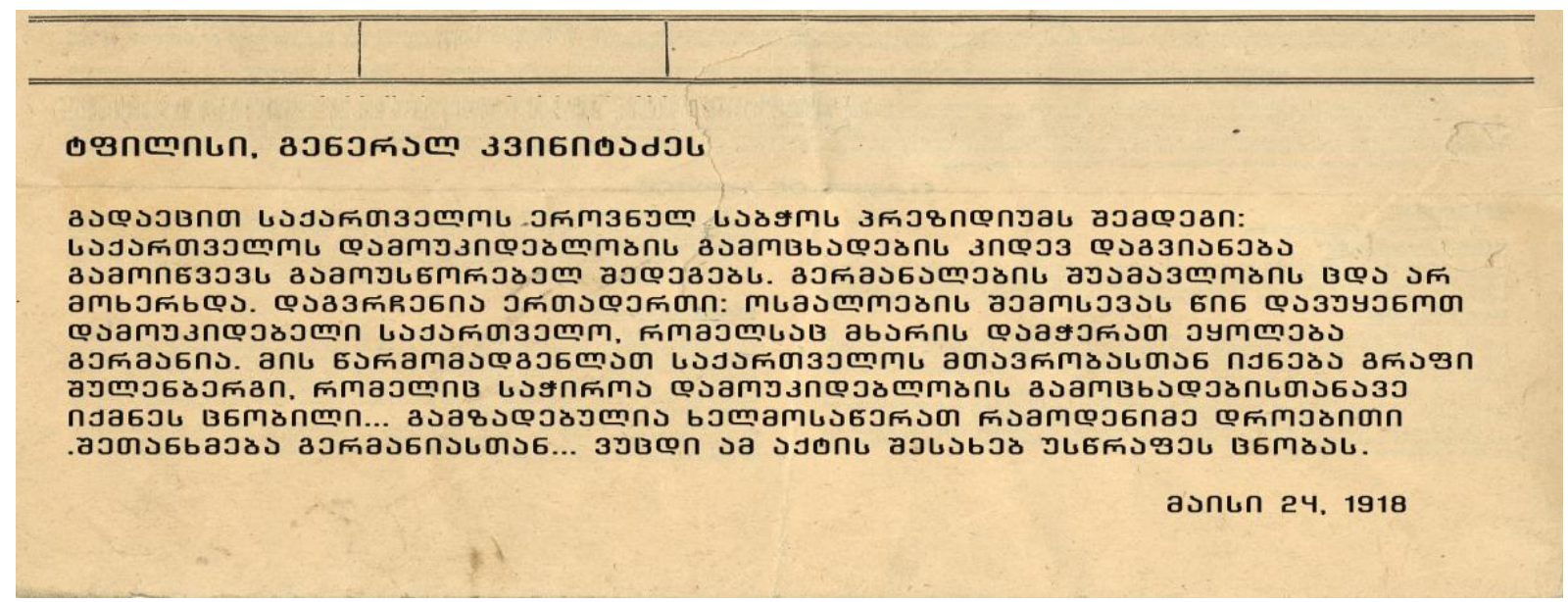




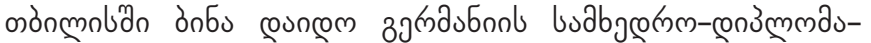
фnๆ

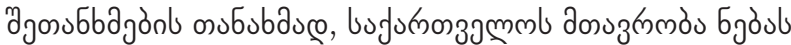

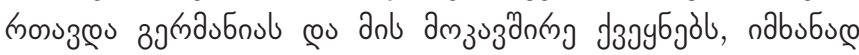

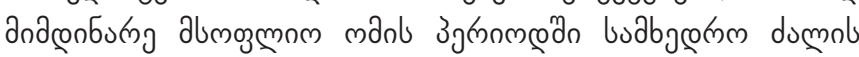

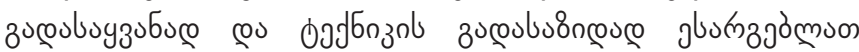

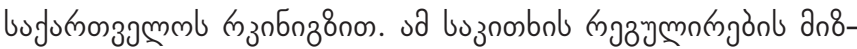

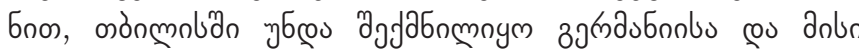

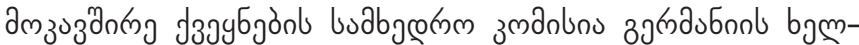

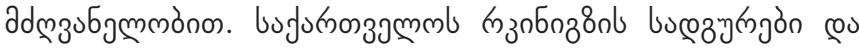
gुmonol buzbuल

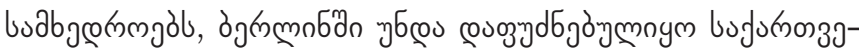
mmb enümmà

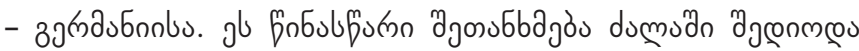
bэmamfignoloos bus 3 .

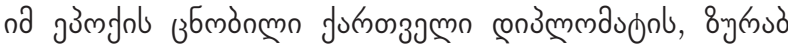

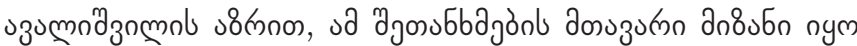

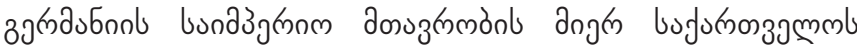

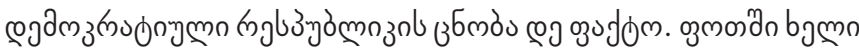
am gुf

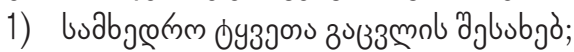

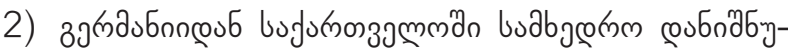

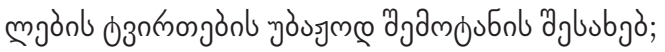

3) bufunnzagmmb ogm

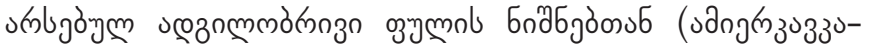

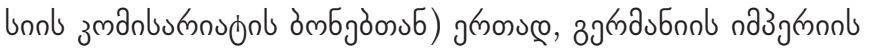

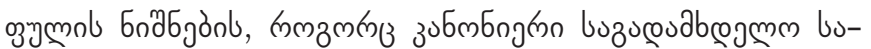

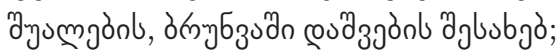

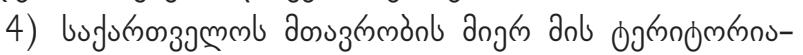
8j aymogn 3 gr coubaumgònb aglusbjo;

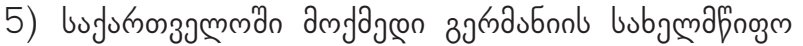
змdnbno b ubs.

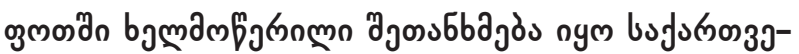

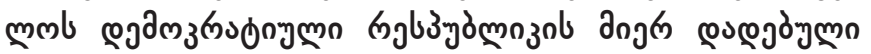

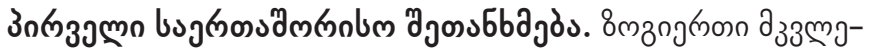

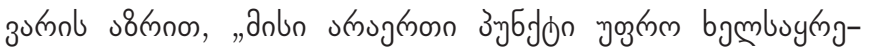

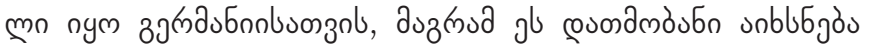

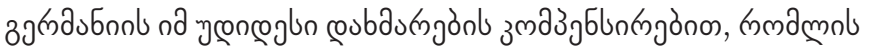

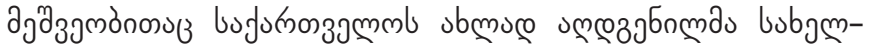

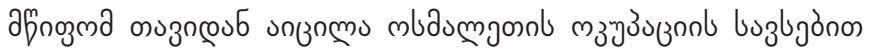

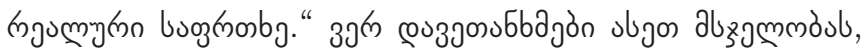

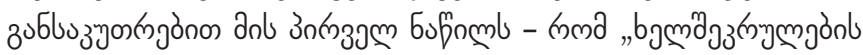

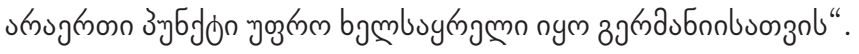

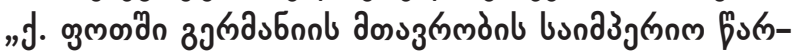

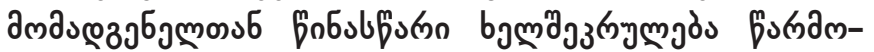
دщзjБణ

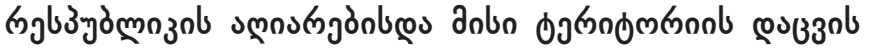

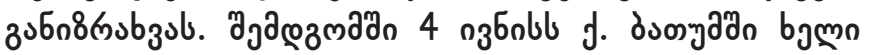

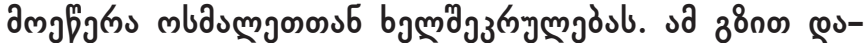

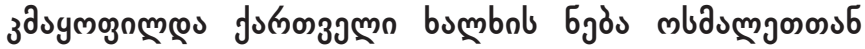

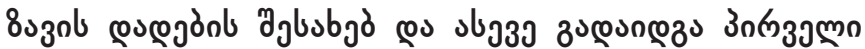

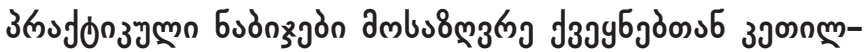

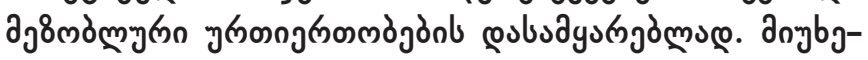

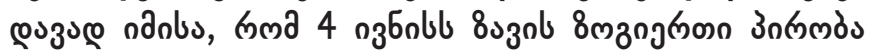

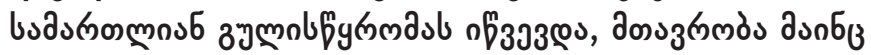

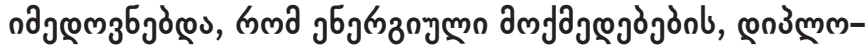

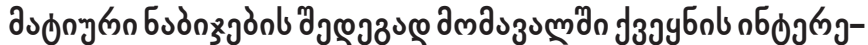
b

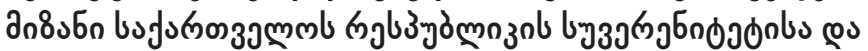

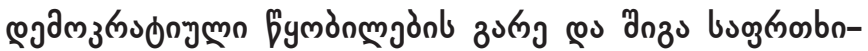
lazar goszzo zapga.

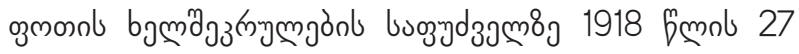

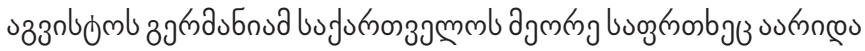

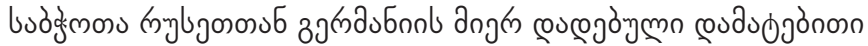

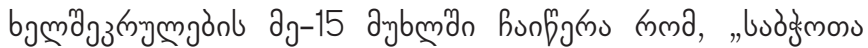

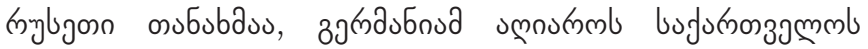

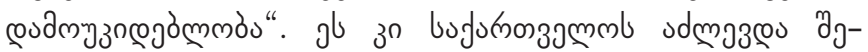

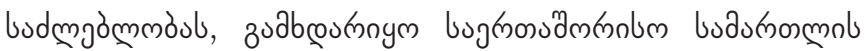

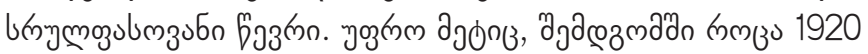

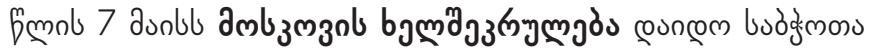

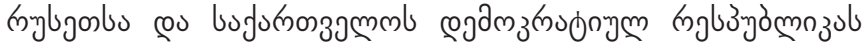

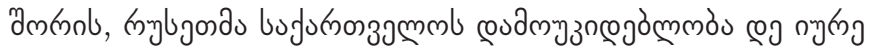

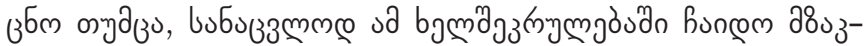

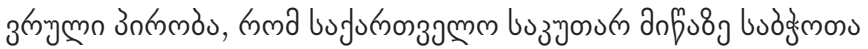

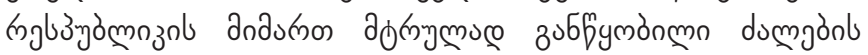
zungallo on zubumuzjón.

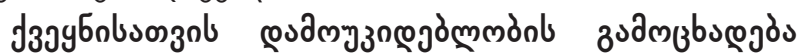
चабпдз

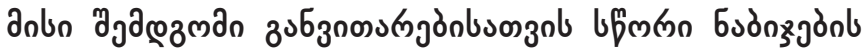

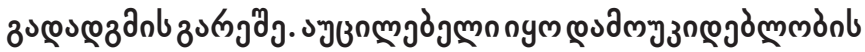

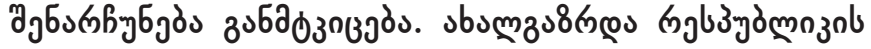

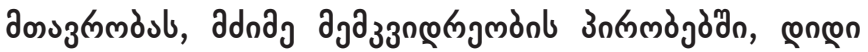

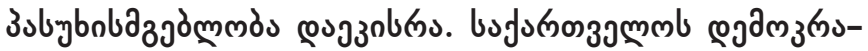

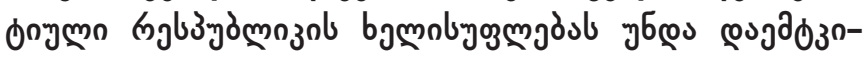

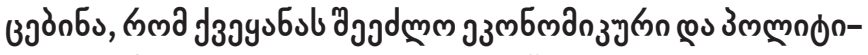

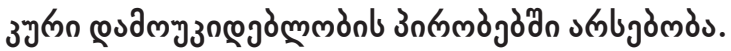

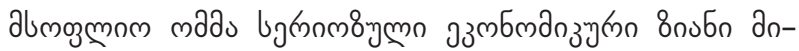

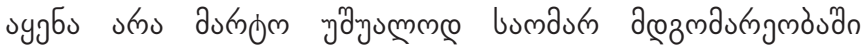

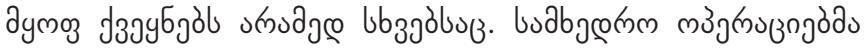

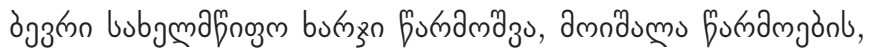

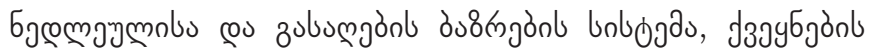

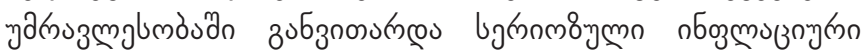

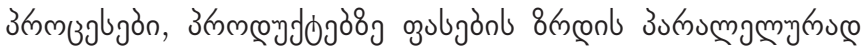

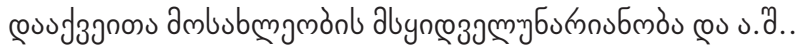

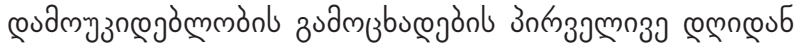

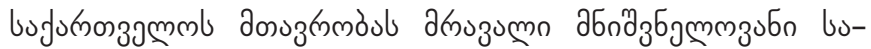

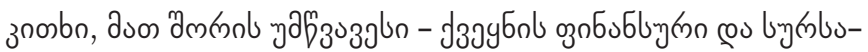

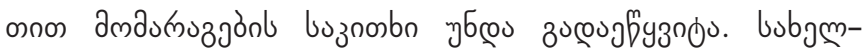




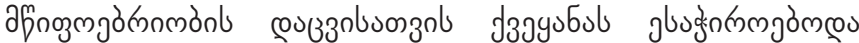

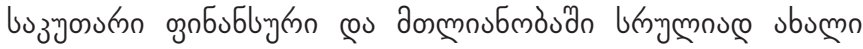

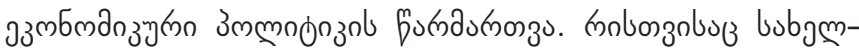

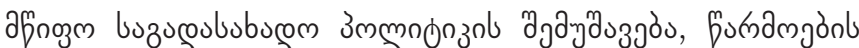

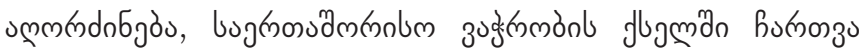

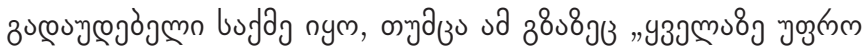

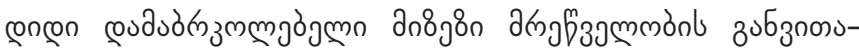

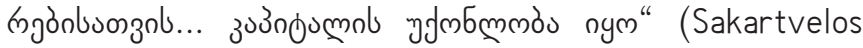
Respublika 1918:60).

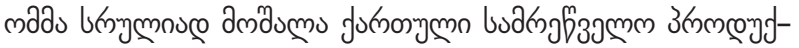

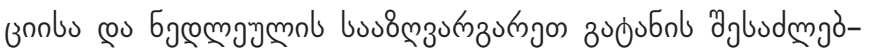

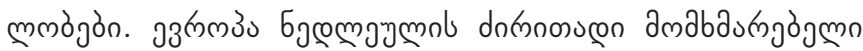

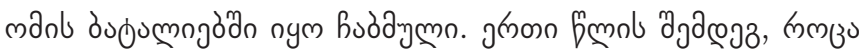

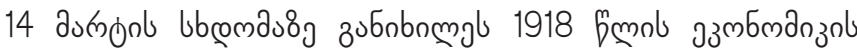

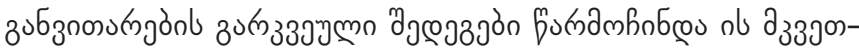

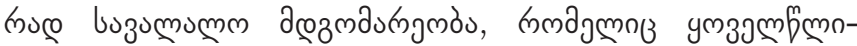

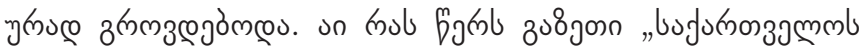

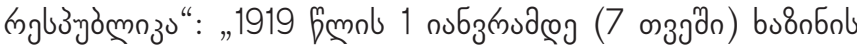

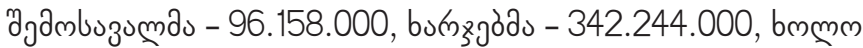

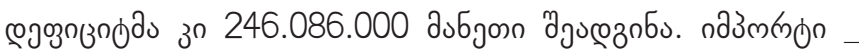
140.929.260, jلflümtron 87.494.105 aubjonol jmmn nym,

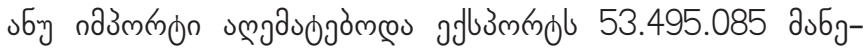

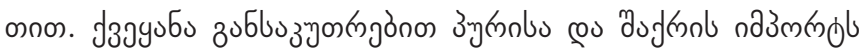

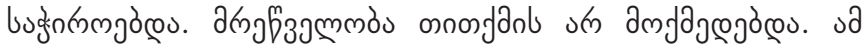

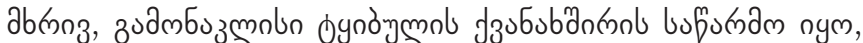

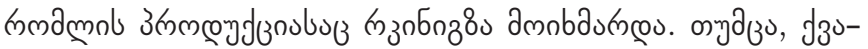

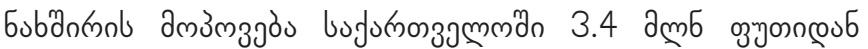

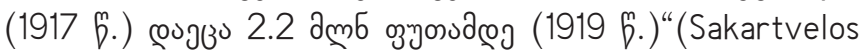
Respublika, 1919: N 11 ).

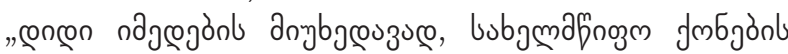

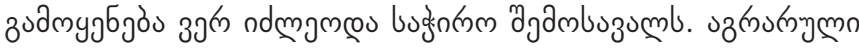

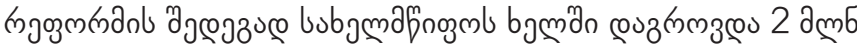

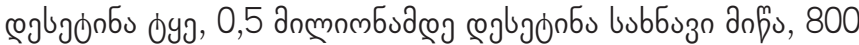

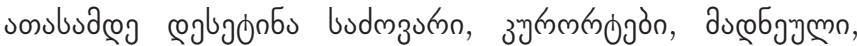

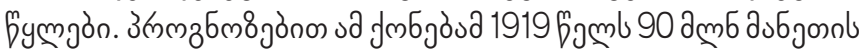

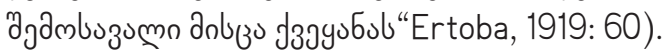

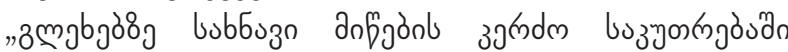

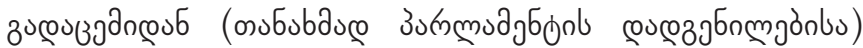

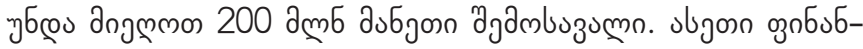

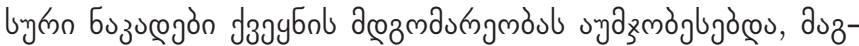

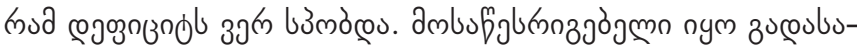

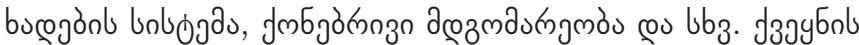

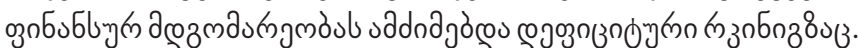

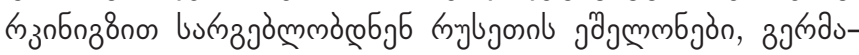

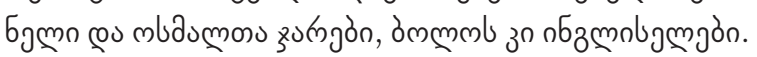

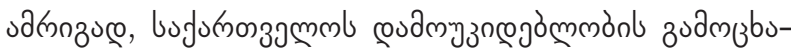

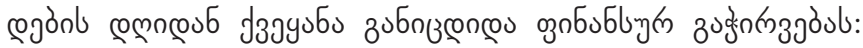

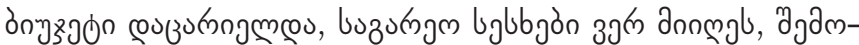

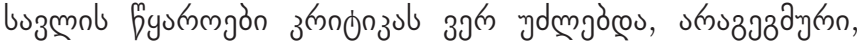

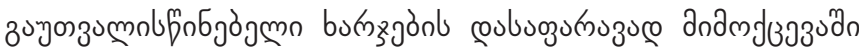

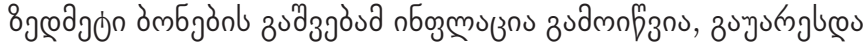

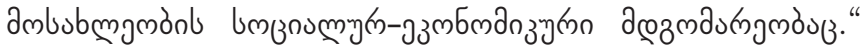
(Tkeshelashvili,1958:106).

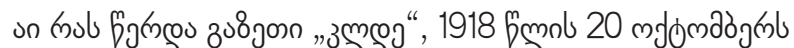

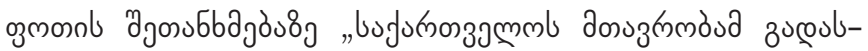

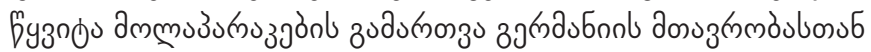

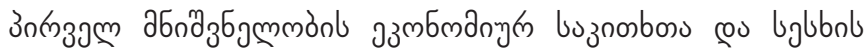

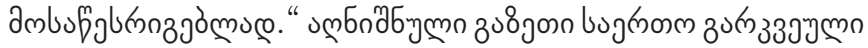

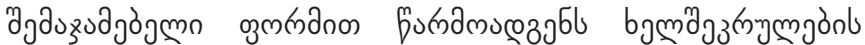

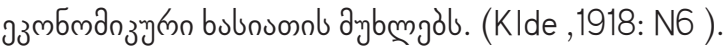

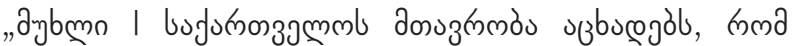

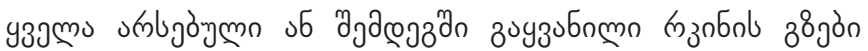

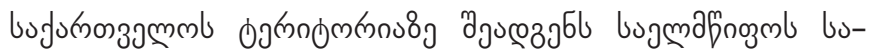

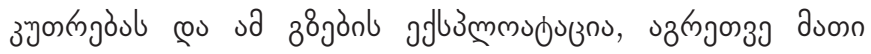

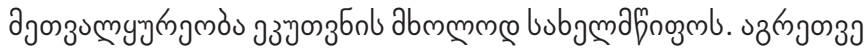

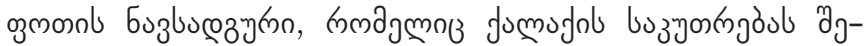
u

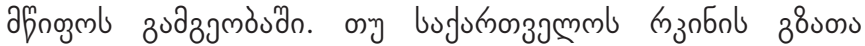

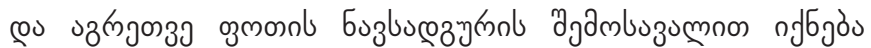

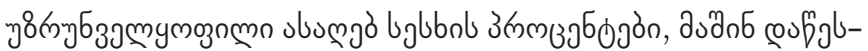

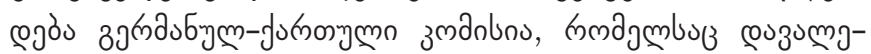

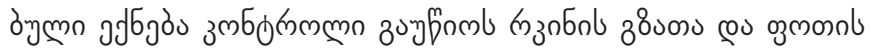

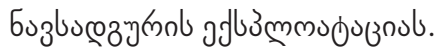

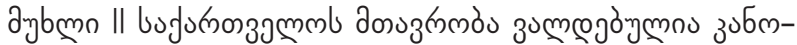

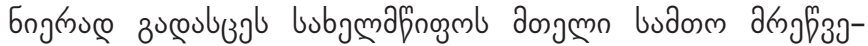

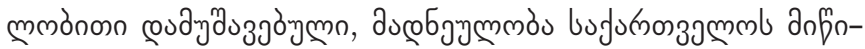

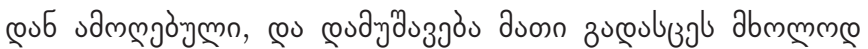

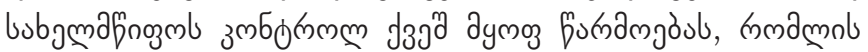

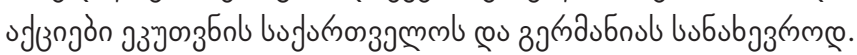

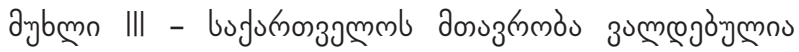

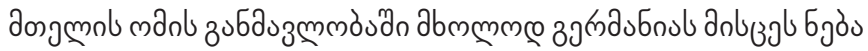

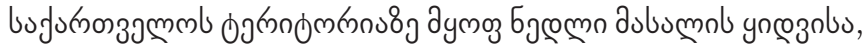

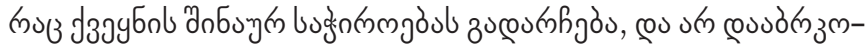

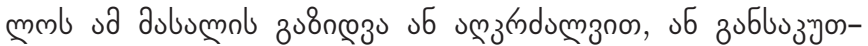

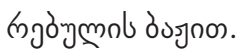

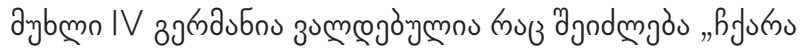

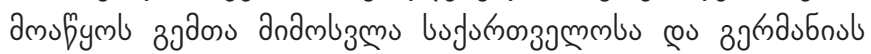

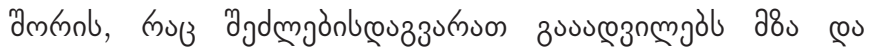

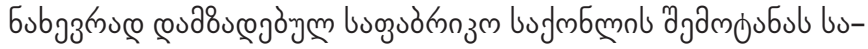
furnos зjलm

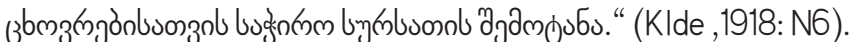

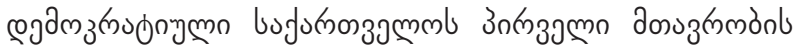

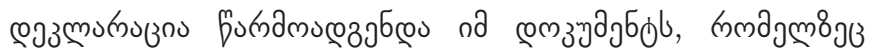

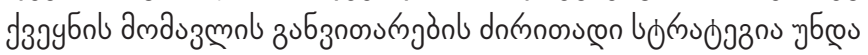

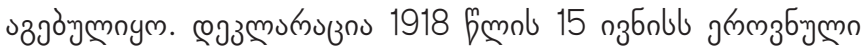

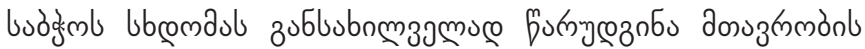

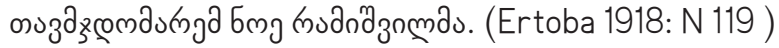

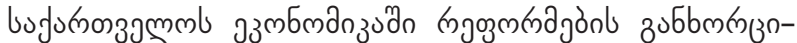

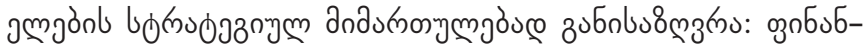

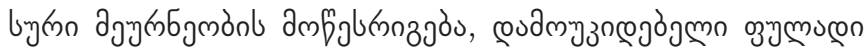




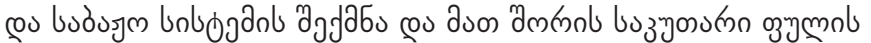

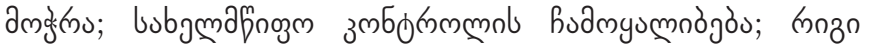

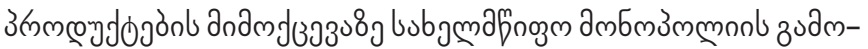

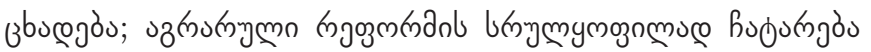

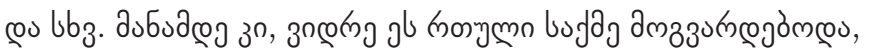

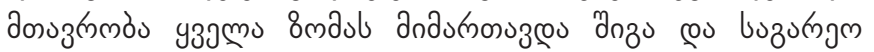
bjubjônb ambu8̊ncue." (Kandelaki, 1960:32).

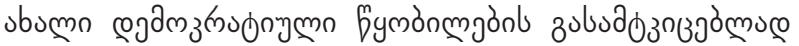

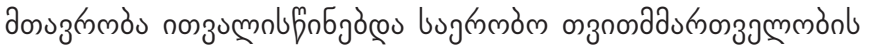

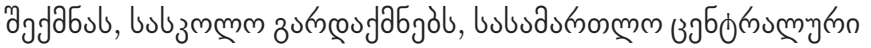

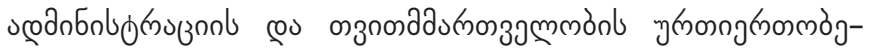

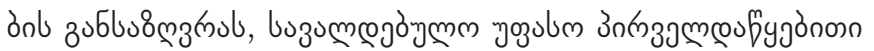

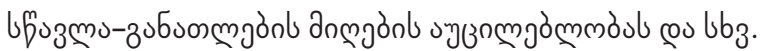

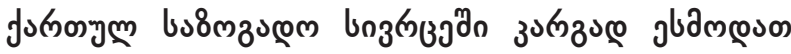

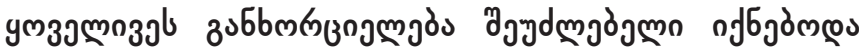

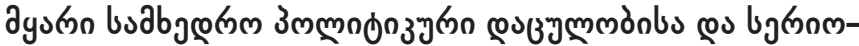

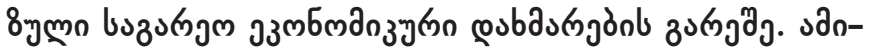

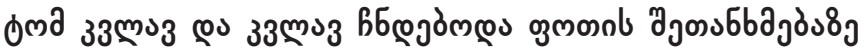

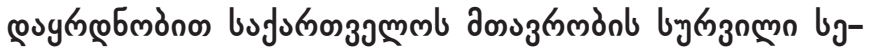

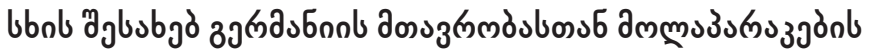

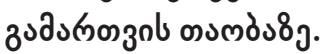

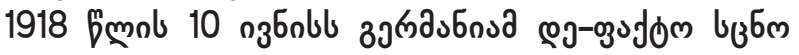

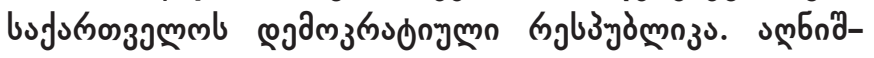

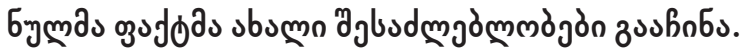

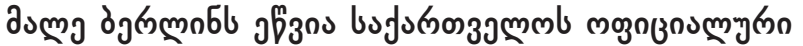

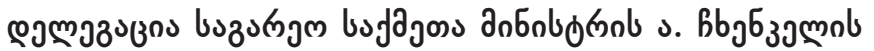

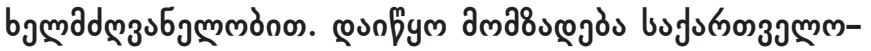

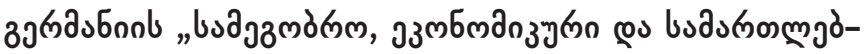

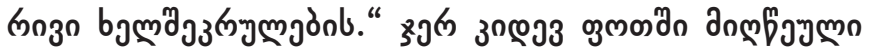

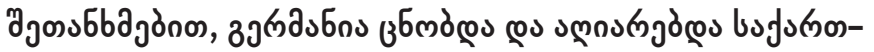

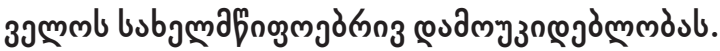

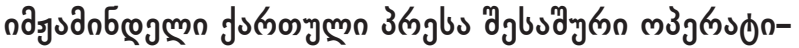

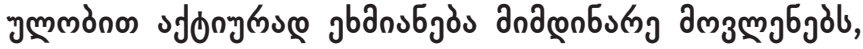

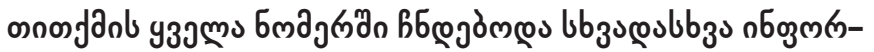

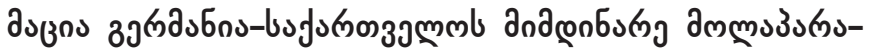

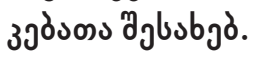

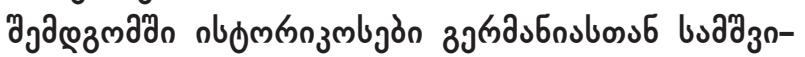

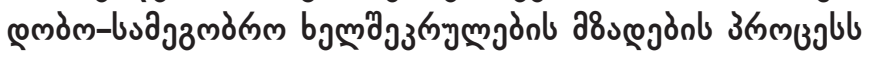

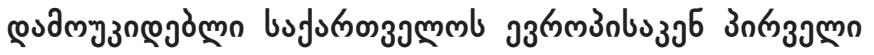

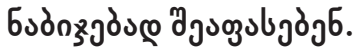

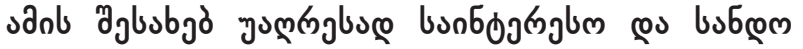

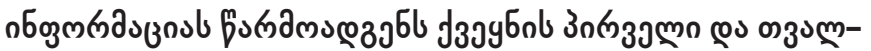

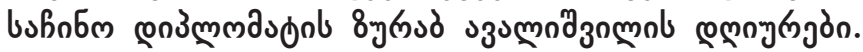

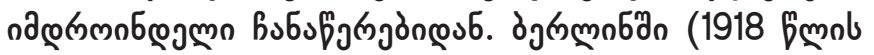
nзбовn).

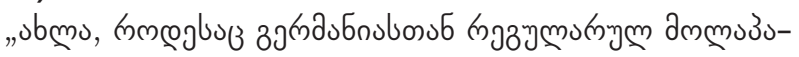

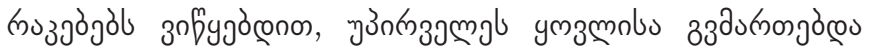

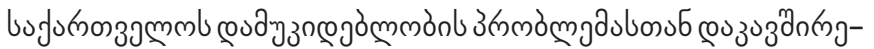

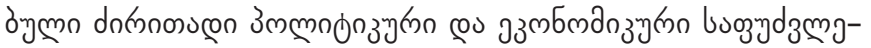

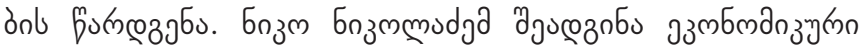

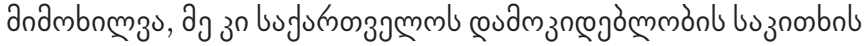

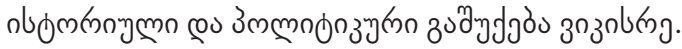

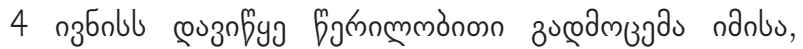

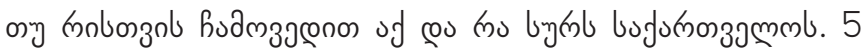

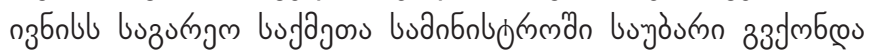

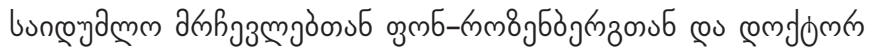

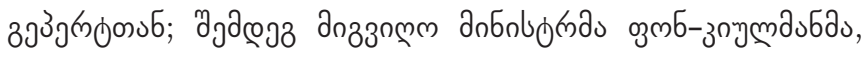

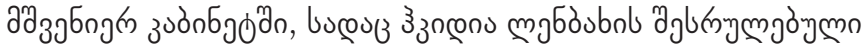

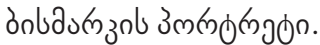

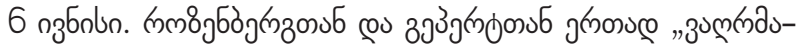

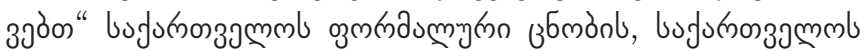

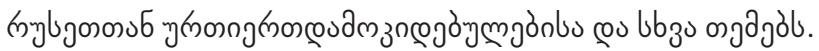

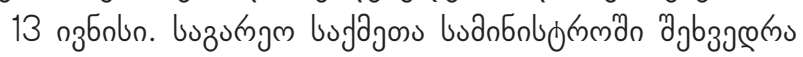

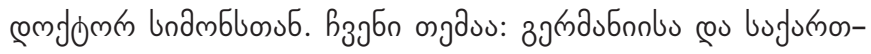

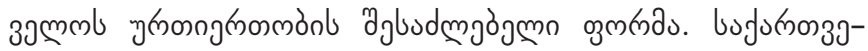

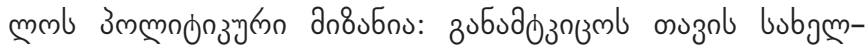

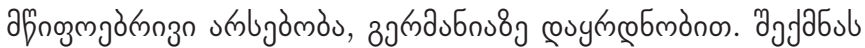

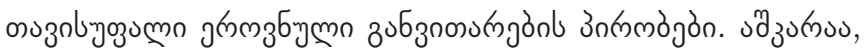

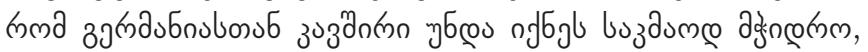

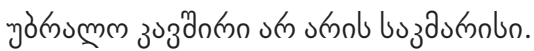

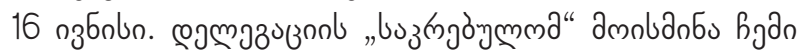

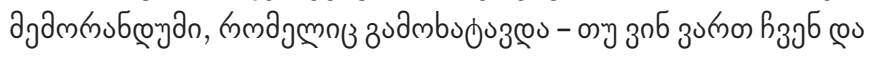

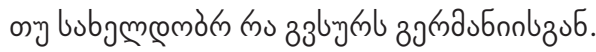

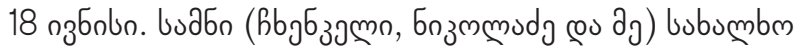

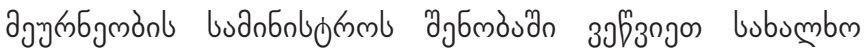

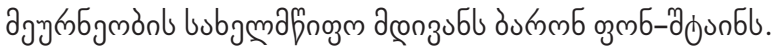

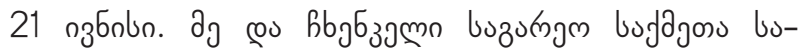

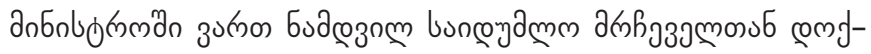

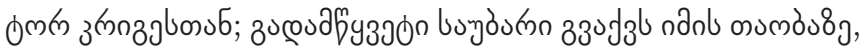

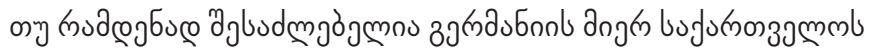

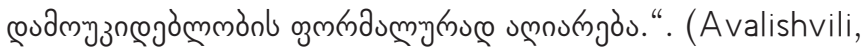
2011).

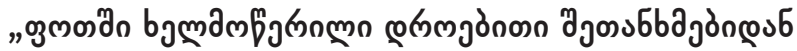

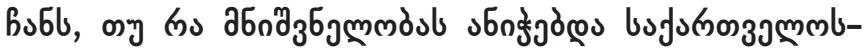

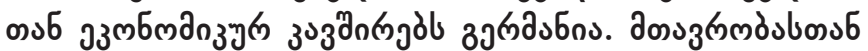

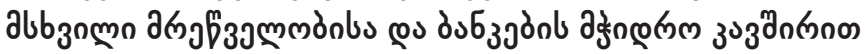

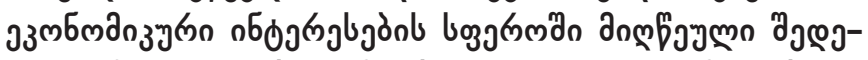

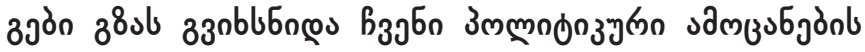

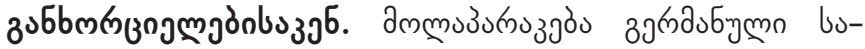

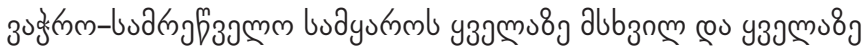

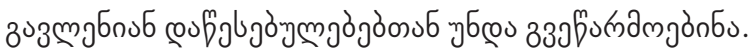

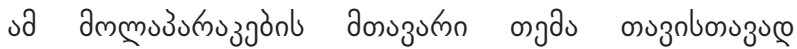

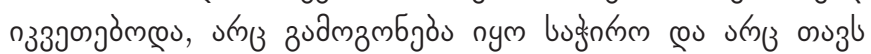

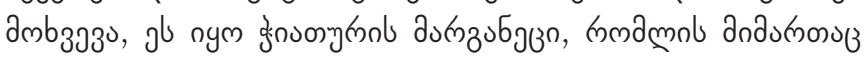

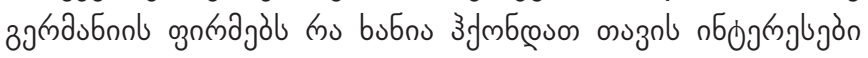

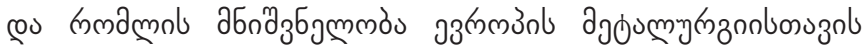

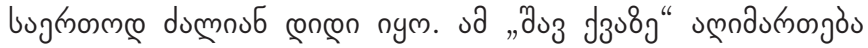

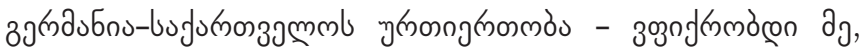

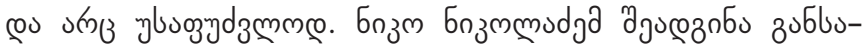

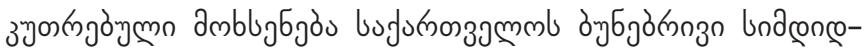




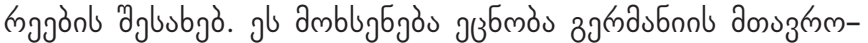

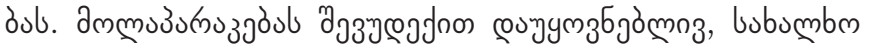

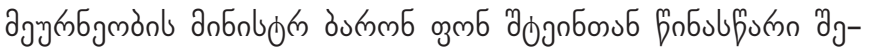

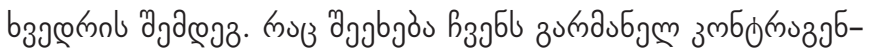

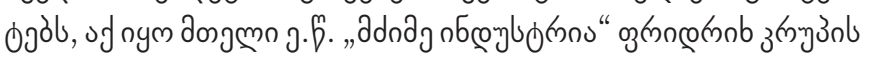

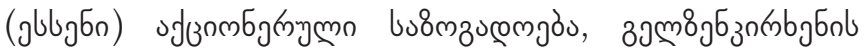

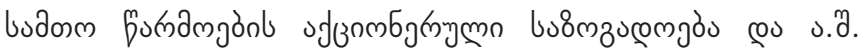

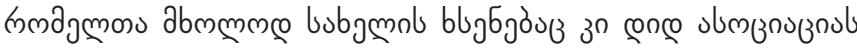

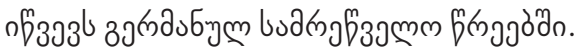

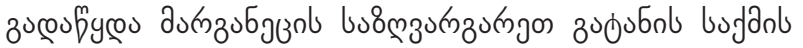

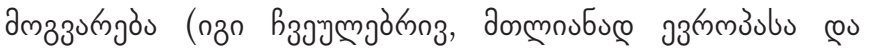

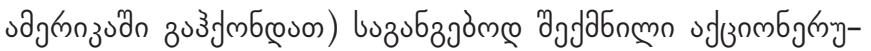

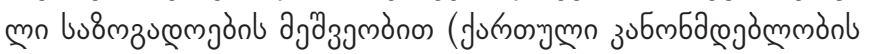

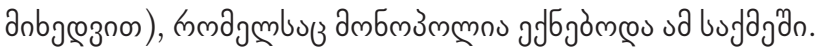

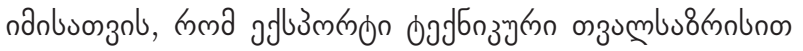

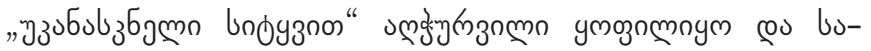

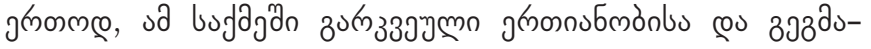

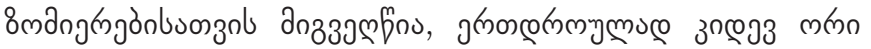

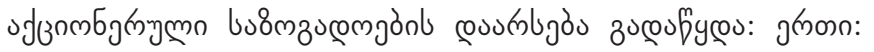

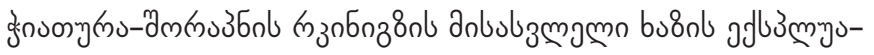

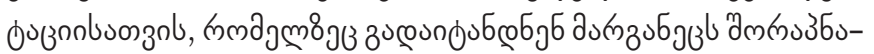

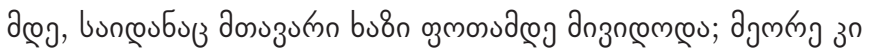

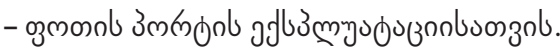

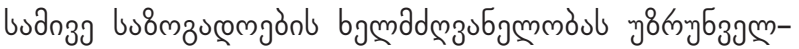

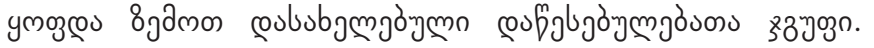

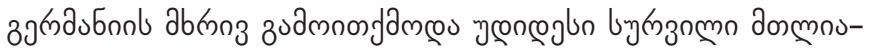

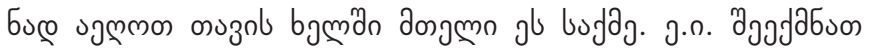

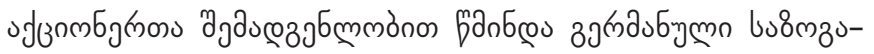

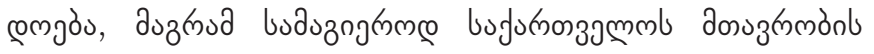

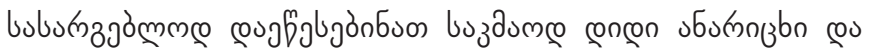

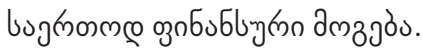

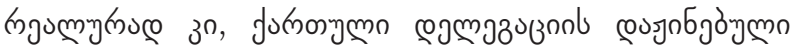

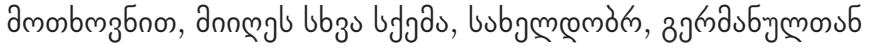

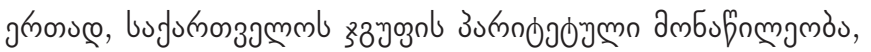

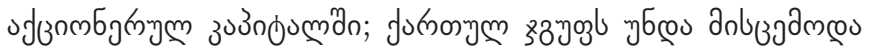

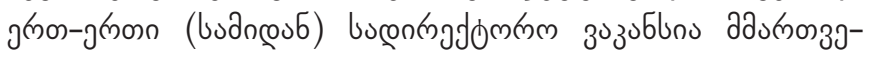

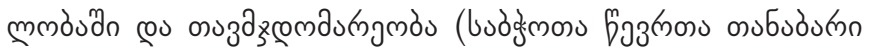

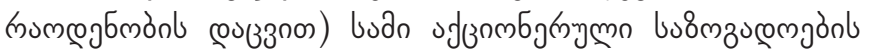

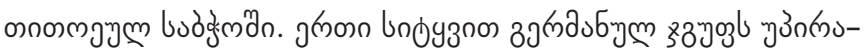

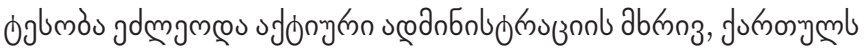

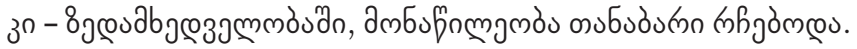

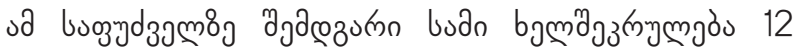

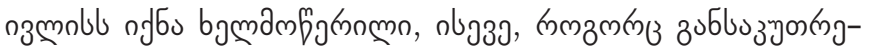

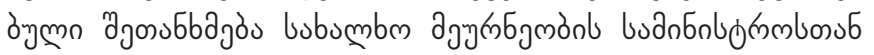

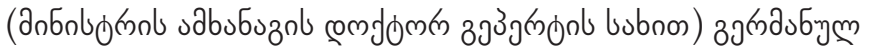

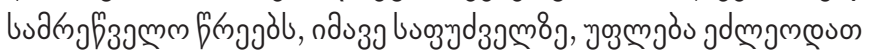

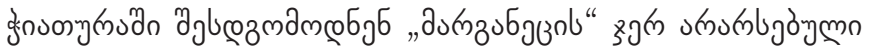

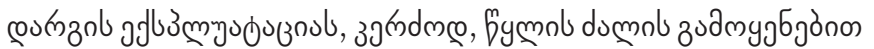

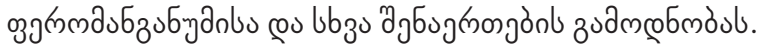

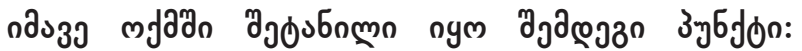

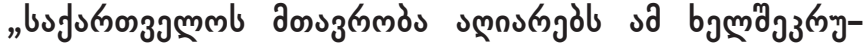

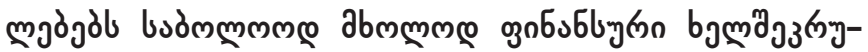

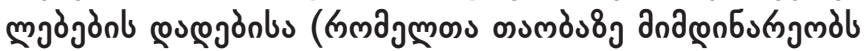

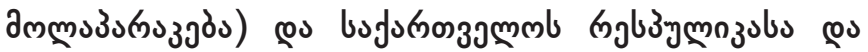

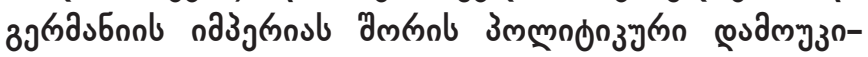

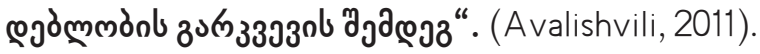

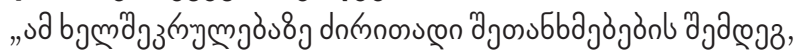

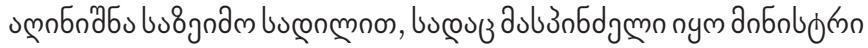

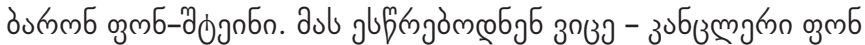

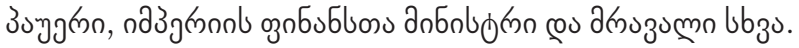

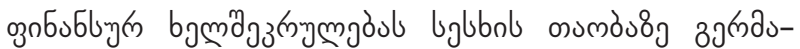
Enol yanuz

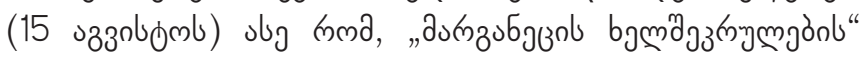

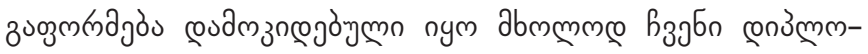

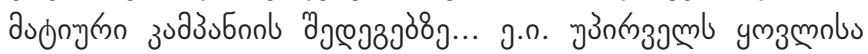

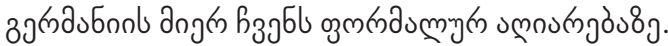

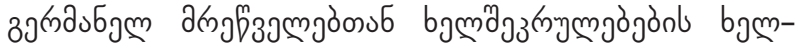

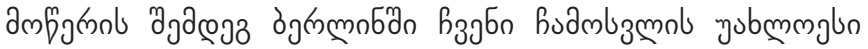

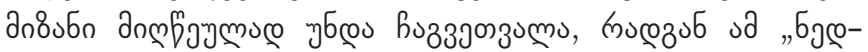

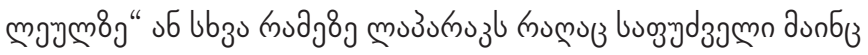

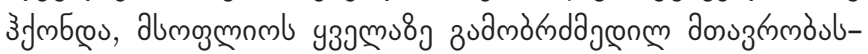

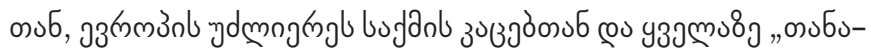

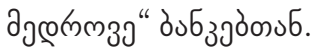

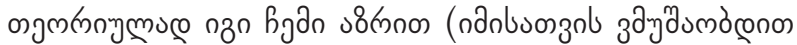

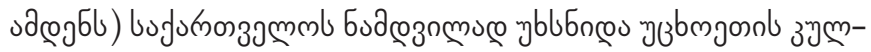

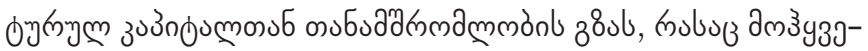

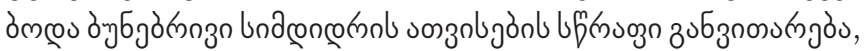

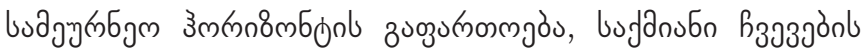

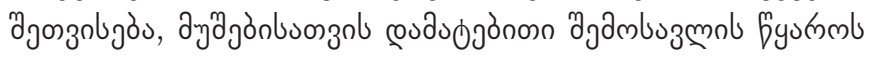
jała6s... co bbzu."(Avalishvili, 2011).

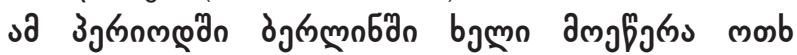

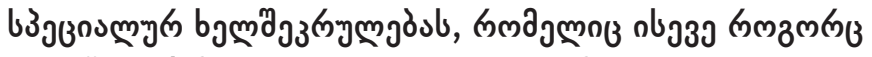

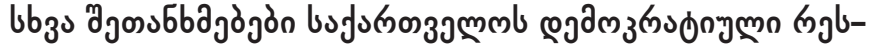

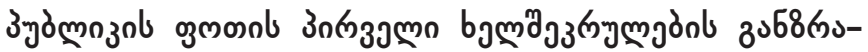

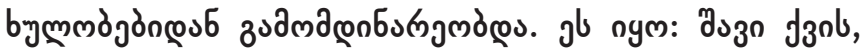

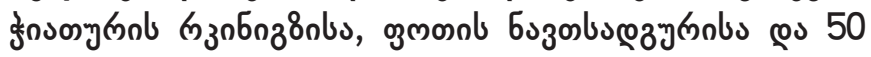

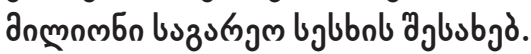

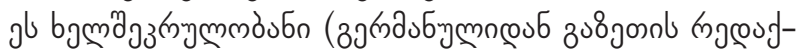

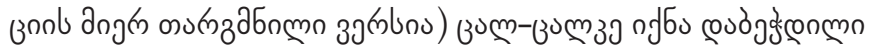

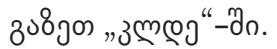

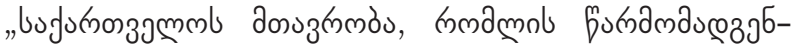

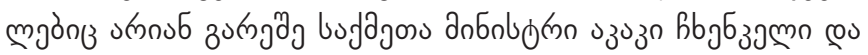

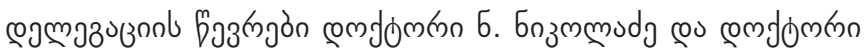

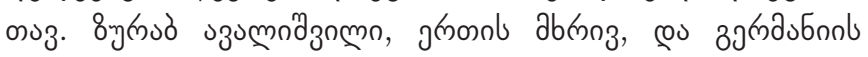

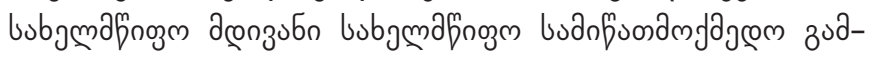

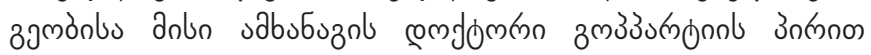

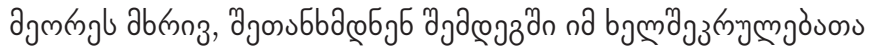

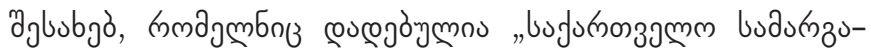

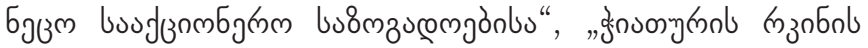

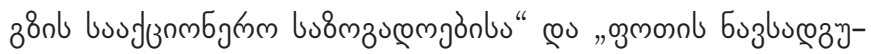




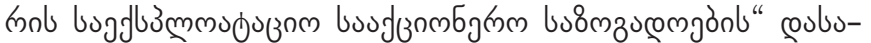

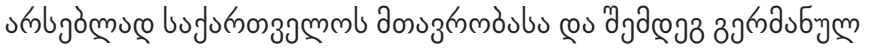

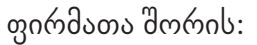

1) "ठgr

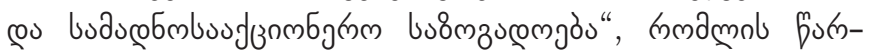

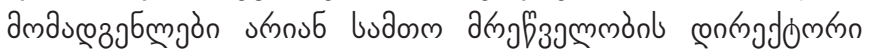

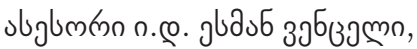

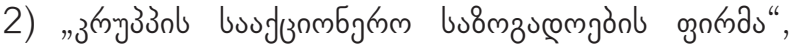

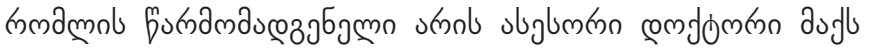

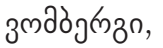

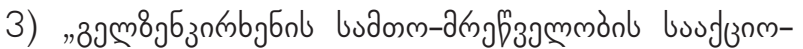

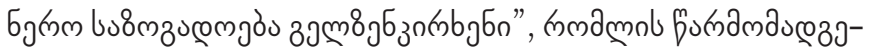

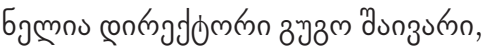

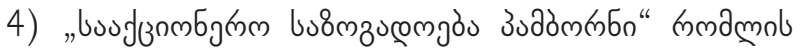

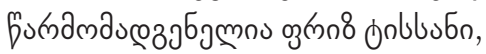

5) "budomm dr

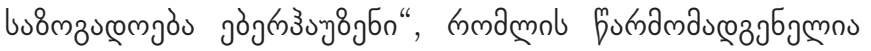

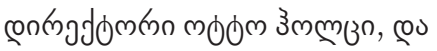

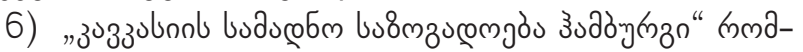

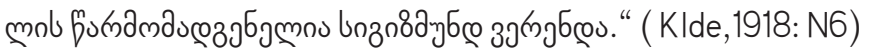

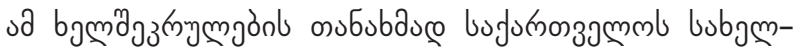

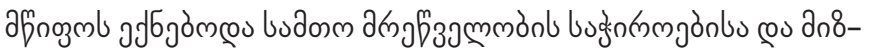

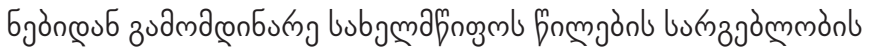

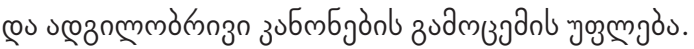

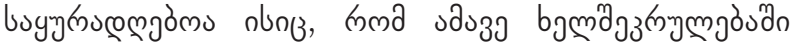

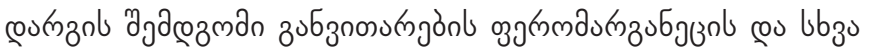

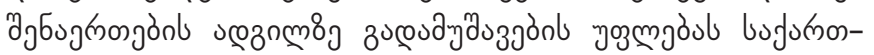

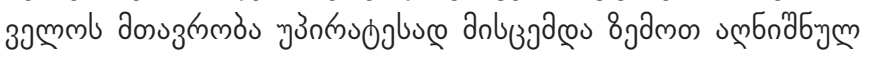

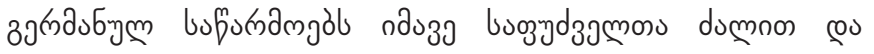

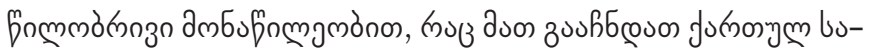

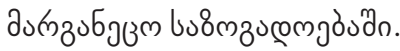

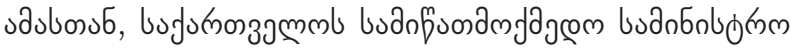

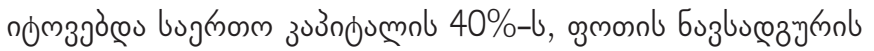

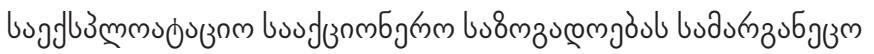

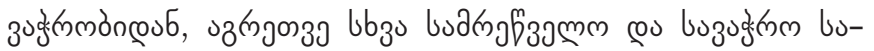

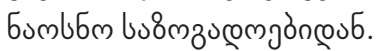

उ

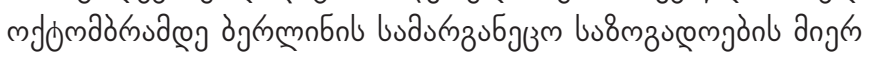

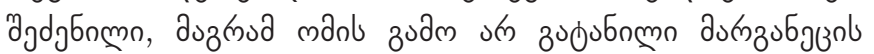

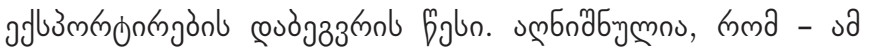

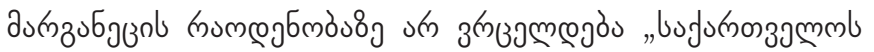

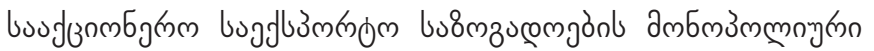

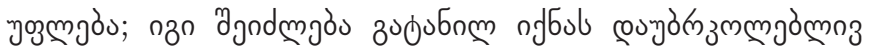

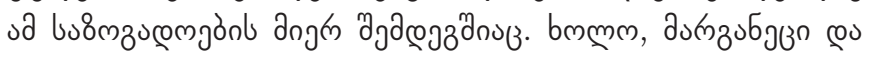

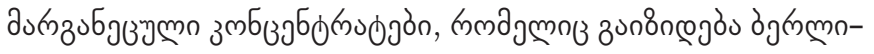

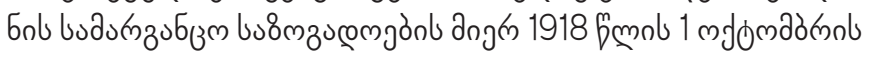

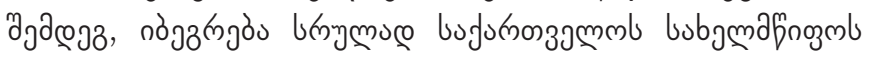

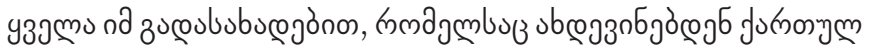

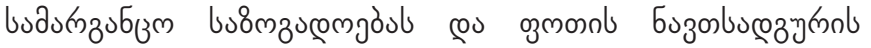

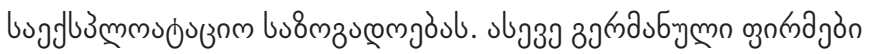

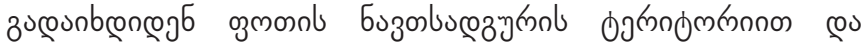

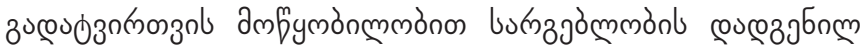
zucoububugojal.

bəm

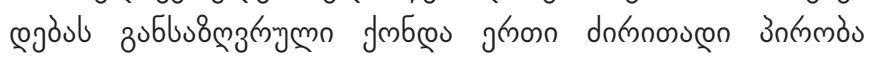

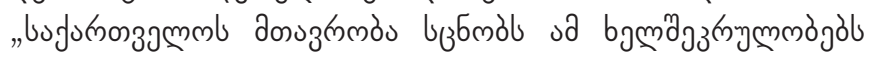

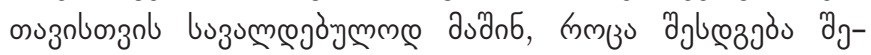

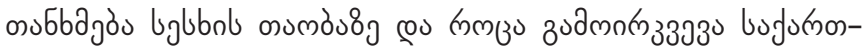

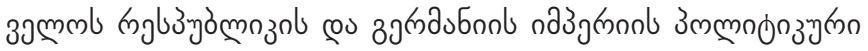

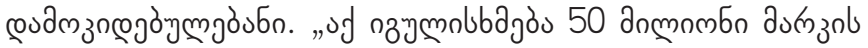

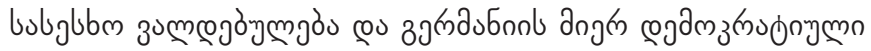

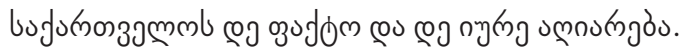

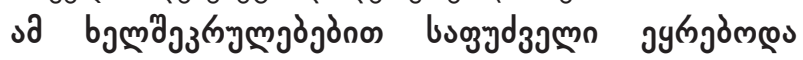

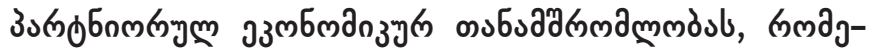

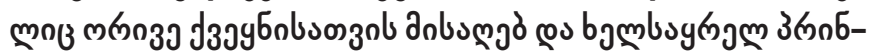

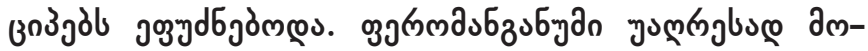

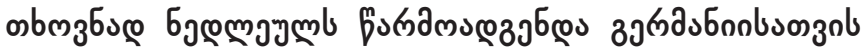

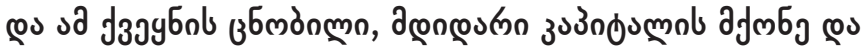

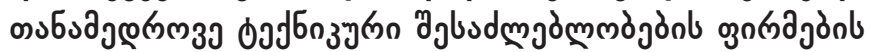

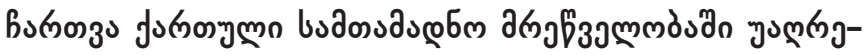

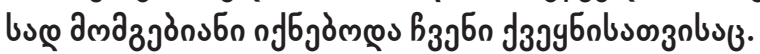

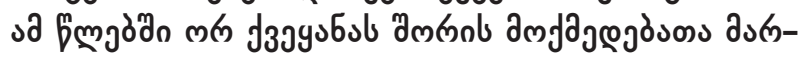

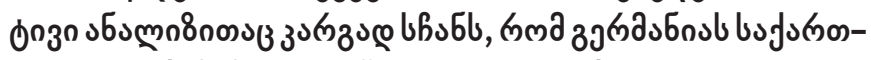

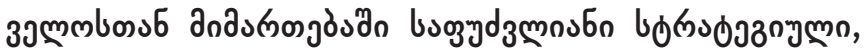

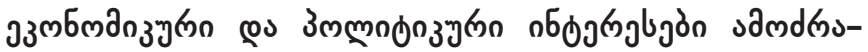

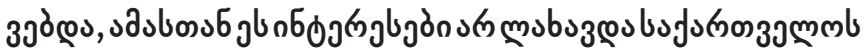

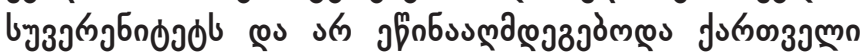

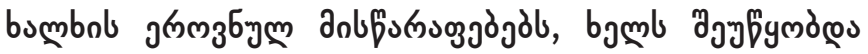

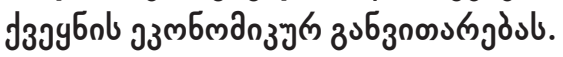

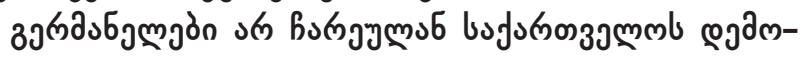

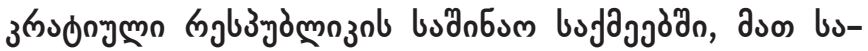

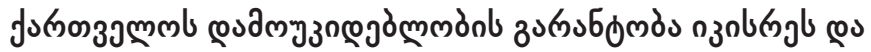

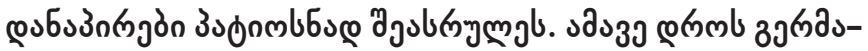

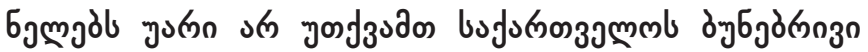

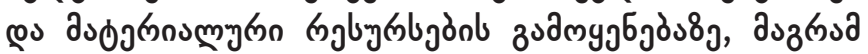

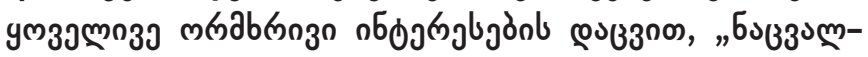

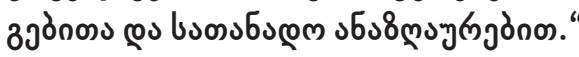

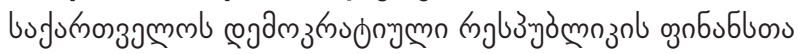

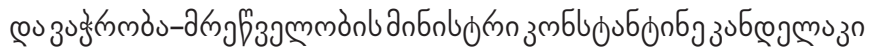

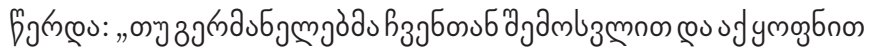

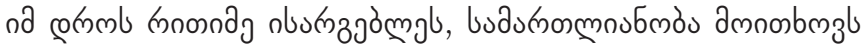

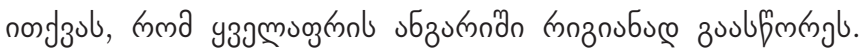

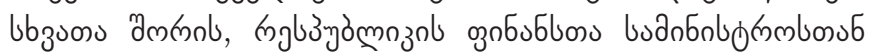

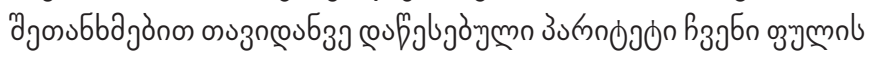

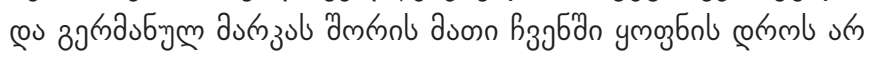

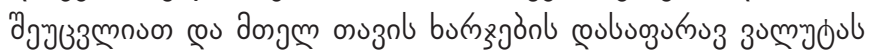

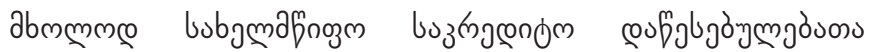

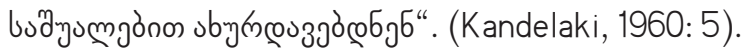

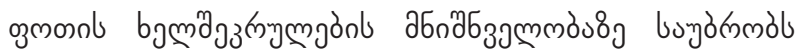

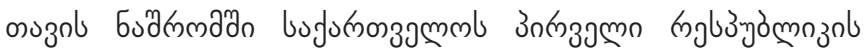




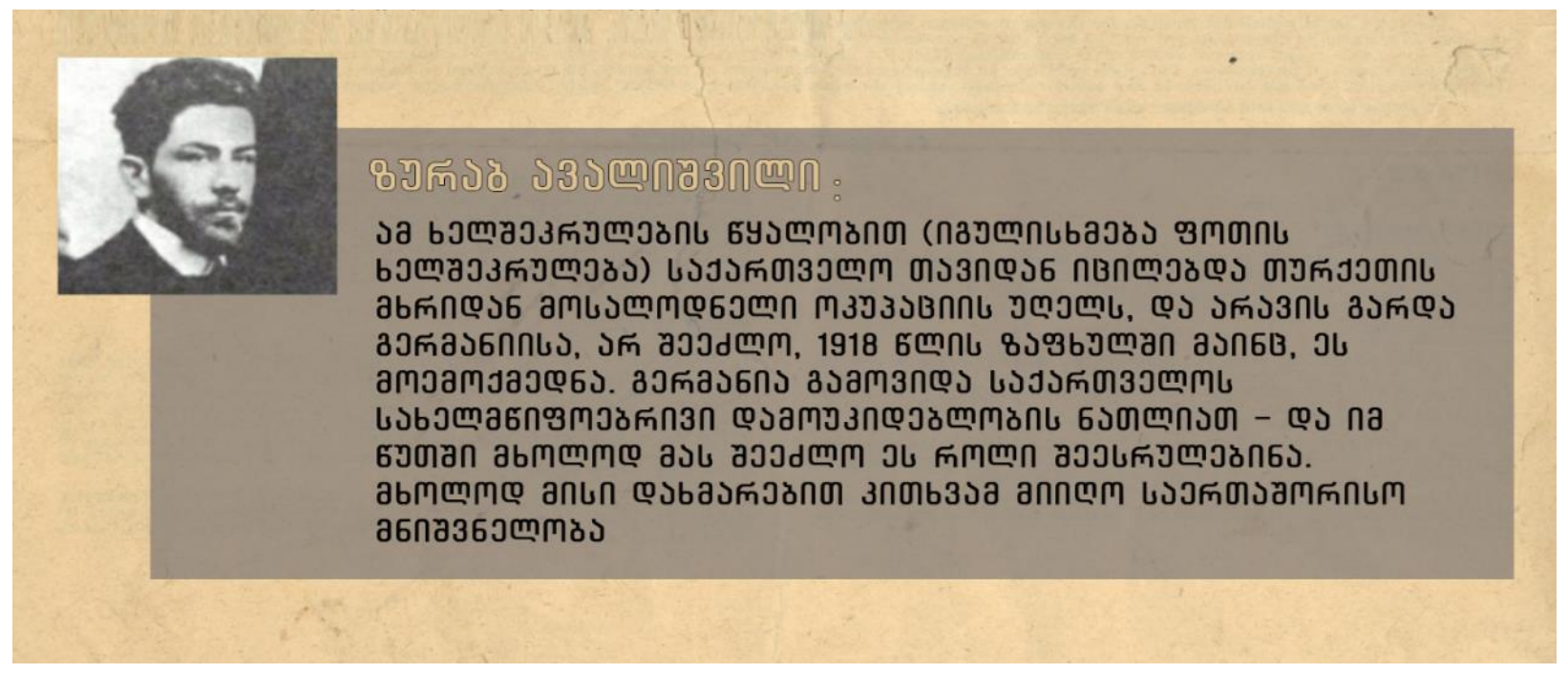

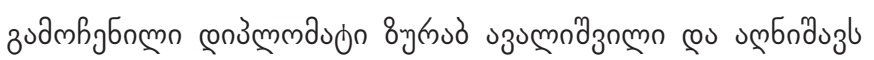

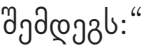

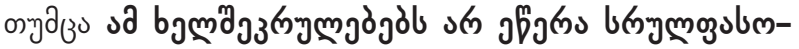

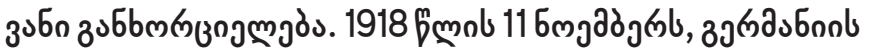

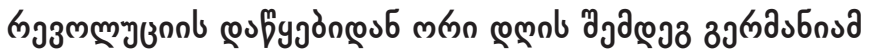

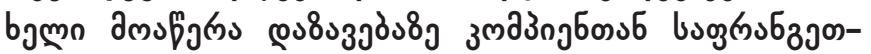

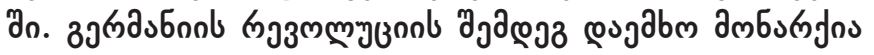

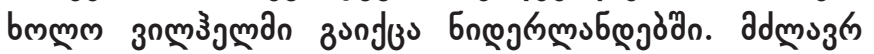

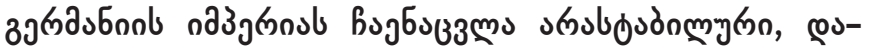

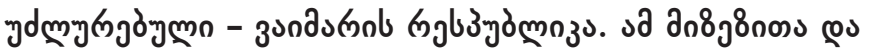

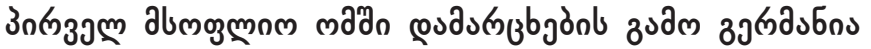

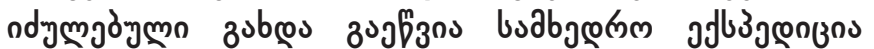

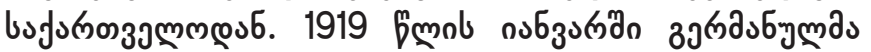

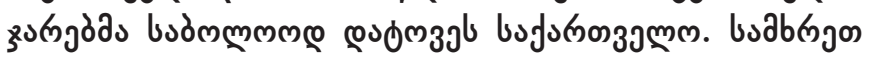

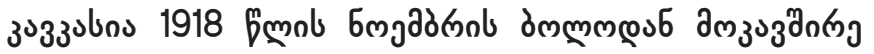

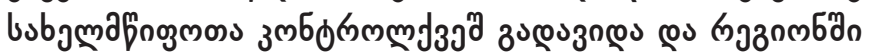

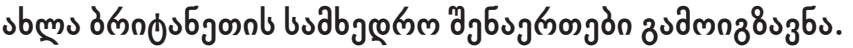

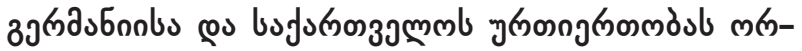

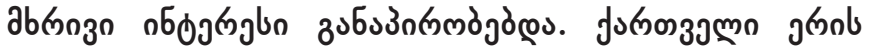

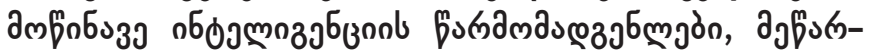

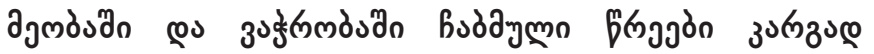

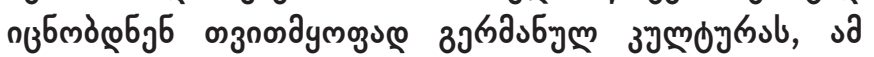

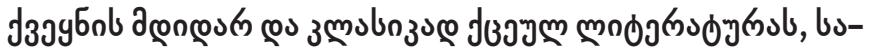

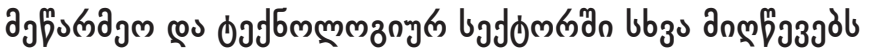
es encose sogubgdeб

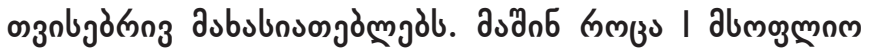

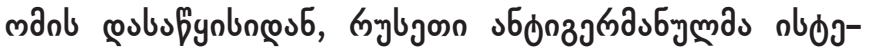

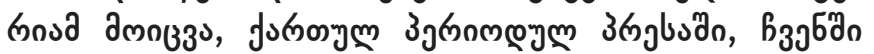

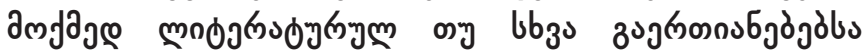

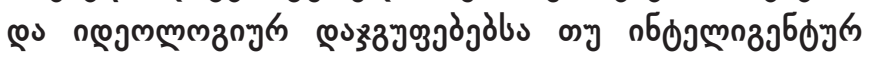

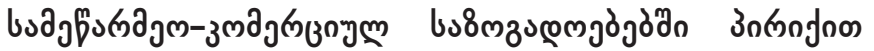

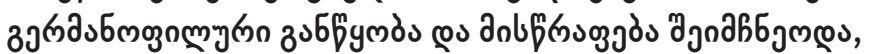

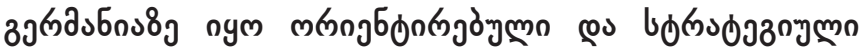

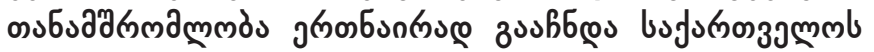

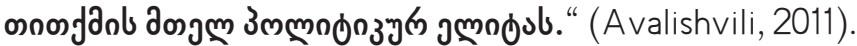

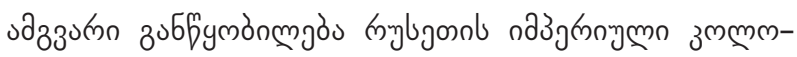

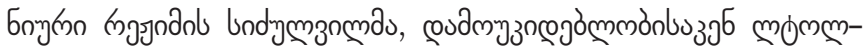

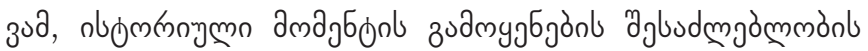

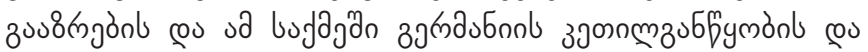

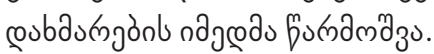

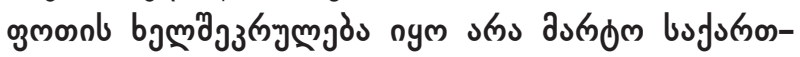

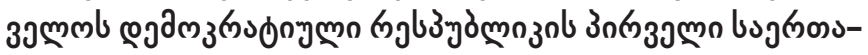

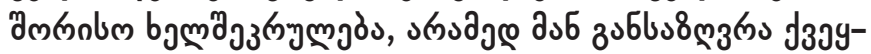

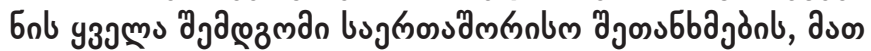

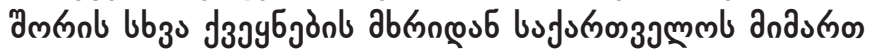

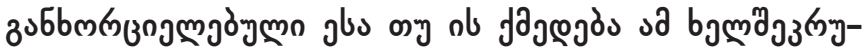

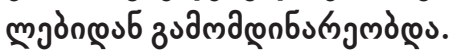

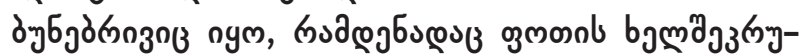

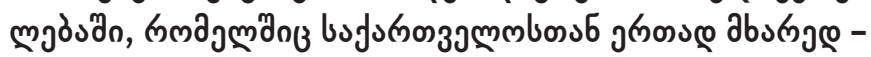

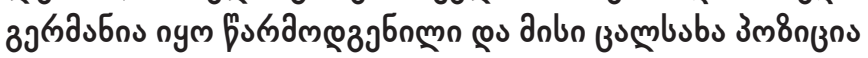

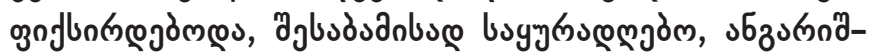

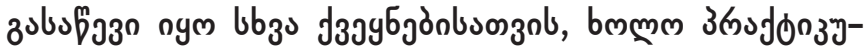

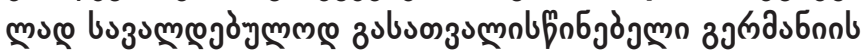

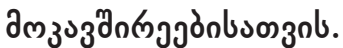

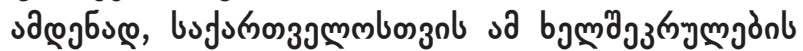

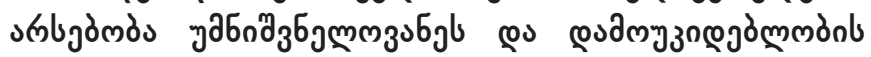

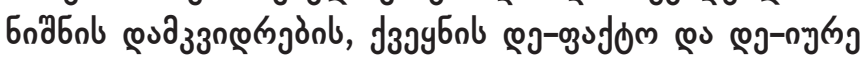

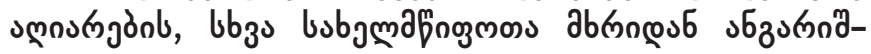

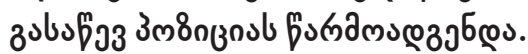

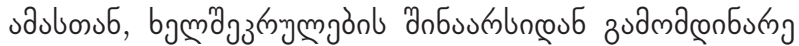

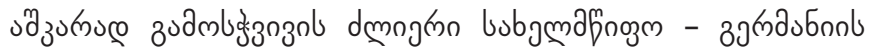

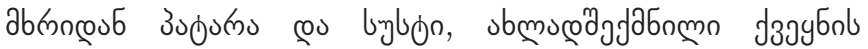

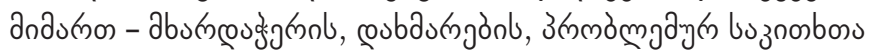

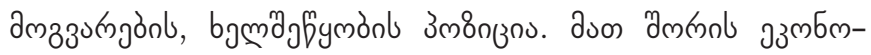

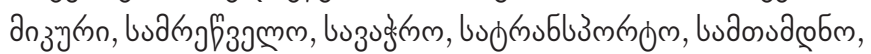

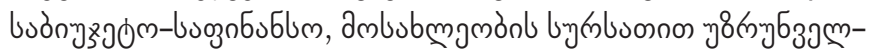

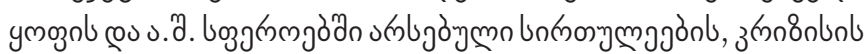

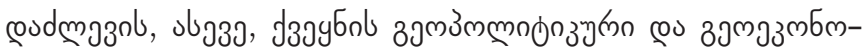

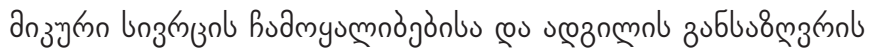
дก85non. 


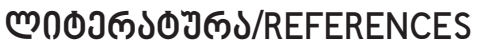

Sakartvelos Respublika (1918). N 11 (In Georgian)

Sakartvelos Respublika (1919). N 4 (In Georgian)

Ertoba (1919). N 60 (In Georgian)

Ertoba (1918). N 119, June 18 (In Georgian)

KIde (1918). N6, October 20 (In Georgian)

Sakhalkho Sakme (1919). July 5 (In Georgian)

Sakartvelo (1918). May 30 (In Georgian)

Sali KIde (1919). May 19 (In Georgian)

Chumburidze, D. (2003). National Liberation Movements of Georgian People at the beginning of XX century 1918

1921. Tbilisi, Edition "Mematiane" (In Georgian)

Kandelaki, K. (1960). Georgian National Economy, Book II, Paris (In Georgian)

Avalishvili, Z. (2011). Independence of Georgia in International Politics 1918-1921. Tbilisi (In Georgian)

Tkeshelashvili, N. (1958). History of Georgian Industry 1860-1920. Tbilisi (In Georgian)

Janelidze, O. (2018). History of Independence of Republic of Georgia. Tbilisi (In Georgian)

Social - political Dictionary (2004). Handbbok, Social Science Centre, Tbilisis, (In Georgian)

History of Georgian Diplomacy (2003). Editor R.Metreveli, Tbilisi: Tbilisi State University Edition (In Georgian) 